NASA/TM-2001-209620

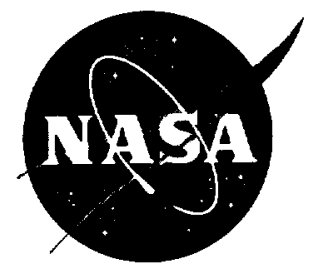

\title{
A Two-Stage-to-Orbit Spaceplane Concept with Growth Potential
}

Unmeel B. Mehta and Jeffrey V. Bowles 
The NASA STI Program Office . . . in Profile

Since its founding, NASA has been dedicated to the advancement of aeronautics and space science. The NASA Scientific and Technical Information (STI) Program Office plays a key part in helping NASA maintain this important role.

The NASA STI Program Office is operated by Langley Research Center, the Lead Center for NASA's scientific and technical information. The NASA STI Program Office provides access to the NASA STI Database, the largest collection of aeronautical and space science STI in the world. The Program Office is also NASA's institutional mechanism for disseminating the results of its research and development activities. These results are published by NASA in the NASA STI Report Series, which includes the following report types:

- TECHNICAL PUBLICATION. Reports of completed research or a major significant phase of research that present the results of NASA programs and include extensive data or theoretical analysis. Includes compilations of significant scientific and technical data and information deemed to be of continuing reference value. NASA's counterpart of peer-reviewed formal professional papers but has less stringent limitations on manuscript length and extent of graphic presentations.

- TECHNICAL MEMORANDUM. Scientific and technical findings that are preliminary or of specialized interest, e.g., quick release reports, working papers, and bibliographies that contain minimal annotation. Does not contain extensive analysis.

- CONTRACTOR REPORT. Scientific and technical findings by NASA-sponsored contractors and grantees.
- CONFERENCE PUBLICATION. Collected papers from scientific and technical conferences, symposia, seminars, or other meetings sponsored or cosponsored by NASA.

- SPECIAL PUBLICATION. Scientific, technical, or historical information from NASA programs, projects, and missions, often concerned with subjects having substantial public interest.

- TECHNICAL TRANSLATION. Englishlanguage translations of foreign scientific and technical material pertinent to NASA's mission.

Specialized services that complement the STI Program Office's diverse offerings include creating custom thesauri, building customized databases, organizing and publishing research results ... even providing videos.

For more information about the NASA STI

Program Office, see the following:

- Access the NASA STI Program Home Page at http://www.sti.nasa.gov

- E-mail your question via the Internet to help@sti.nasa.gov

- Fax your question to the NASA Access Help Desk at (301) 621-0134

- Telephone the NASA Access Help Desk at (301) 621-0390

- Write to: NASA Access Help Desk NASA Center for AeroSpace Information 7121 Standard Drive Hanover, MD 21076-1320 
NASA/TM-2001-209620

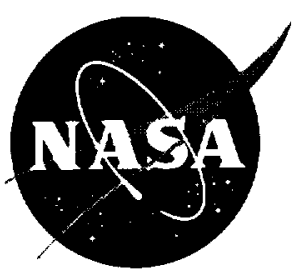

\section{A Two-Stage-to-Orbit Spaceplane Concept with Growth Potential}

Unmeel B. Mehta

Ames Research Center, Moffett Field, California

Jeffrey V. Bowles

Ames Research Center, Moffett Field, California

National Aeronautics and

Space Administration

Ames Research Center

Moffett Field, California 94035-1000 


\section{Acknowledgments}

While at the NASP National Program Office, Unmeel B. Mehta advocated that the NASP program should set aside the SSTO requirement and develop a TSTO spaceplane with air-breathing propulsion on the first stage. Subsequently, Thomas J. Gregory directed at NASA Ames Research Center the development of the TSTO spaceplane concept for the NASA access to space study. The authors thank Thomas J. Gregory (retired), Howard E. Goldstein (retired), William D. Henline, and David J. Kinney of NASA Ames Research Center, William J. D. Escher of Scientific Applications International Corporation, and Henry G. Adelman of ELORET Corporation for their helpful comments and suggestions when they reviewed the Manuscript of this paper.

This paper is presented as AIAA Paper 2001-1795 at the AIAANAL-NASDA-ISAS 10th International Space Planes and Hypersonic Systems and Technologies Conference, 24-27 April 2001, Kyoto, Japan.

Available from:

NASA Center for AeroSpace Information 7121 Standard Drive

Hanover, MD 21076-1320

(301) 621-0390
National Technical Information Service 5285 Port Royal Road Springfield, VA 22161 (703) $487-4650$ 


\title{
A TWO-STAGE-TO-ORBIT SPACEPLANE CONCEPT WITH GROWTH POTENTIAL
}

\author{
Unmeel B. Mehta and Jeffrey V. Bowles \\ NASA Ames Research Center, Moffett Field, Califomia, U.S.A.
}

\begin{abstract}
A two-stage-to-orbit (TSTO) spaceplane concept developed in 1993 is revisited, and new information is provided to assist in the development of the nextgeneration space transportation vehicles. The design philosophy, TSTO spaceplane concept, and the design method are briefly described. A trade study between cold and hot structures leads to the choice of cold structures with external thermal protection systems. The optimal Mach number for staging the second stage of the TSTO spaceplane (with air-breathing propulsion on the first stage) is 10 , based on life-cycle cost analysis. The performance and specification of a prototype/ experimental $(\mathrm{P} / \mathrm{X})$ TSTO spaceplane with a turbo/ram/scramjet propulsion system and built-in growth potential are presented and discussed. The internal rate of return on investment is the highest for the proposed TSTO spaceplane, vis-à-vis a singlestage-to-orbit (SSTO) rocket vehicle and a TSTO spaceplane without built-in growth. Additional growth potentials for the proposed spaceplane are suggested. This spaceplane can substantially decrease access-tospace cost and risk, and increase safety and reliability in the near term. It can be a serious candidate for the nextgeneration space transportation system.
\end{abstract}

\section{Introduction}

In 1959, the request for recoverable booster system, with a goal of routine access to space, led to the Recoverable Orbital Launch System (Aerospace Plane) program in the United States (U.S.).' The U.S. Air Force emphasized two-stage-to-orbit (TSTO) concepts as first-generation options, based on guidance from the Air Force Scientific Advisory Board (SAB) and other ad hoc committees. In November 1965, after intensive study, review, and evaluation, the TSTO approach (airbreathing first stage with a conventional rocket second stage) was selected as the preferred approach. In 1970, when the U.S. Space Shuttle Phase B award began, the National Aeronautics and Space Administration (NASA) and contractors were generally unanimous in considering TSTO fully reusable vehicles as the vehicle of choice. ${ }^{2}$ In 1993, RAND believed that the 1965 choice by the U.S. Air Force was commendable and that it would be a strong contender for developing the X-30 spaceplane under the National Aero-Space Plane (NASP) program.' In 1993, after reviewing the status of X-30, the U.S. General Accounting Office (GAO) recommended a re-examination of the worth of pursing single-stage-to-orbit (SSTO) on its own merit. ${ }^{3}$ In 1994 , Ben Rich expressed that Orient Express (X-30) is actually two separate concepts, one a rocketship and the other an airplane. "Most likely, that particular twain shall never meet successfully." ${ }^{, 4}$ Based on state-of-theart hypersonic technologies, ${ }^{3.5 .6}$ the SSTO concept is an extreme technical challenge, and its commercial viability is highly questionable in the near term. Nevertheless, the SSTO concept is still advocated.

Today, the choice of TSTO concept as the near-term option, with initial operational capability (IOC) in circa 2012, appears to be the correct one. In 1993, a spaceplane based on the TSTO concept was conceptualized for the Access to Space-Advanced Technology Team. ${ }^{8}$ Reference 9 briefly describes this spaceplane. Reference 10 presents a strategy for developing air-breathing spaceplanes, using a TSTO spaceplane concept. Essential aspects of this concept and of this strategy are revisited, and additional information, some based on subsequent work, is provided herein for consideration to assist in the development of next-generation spaceplanes.

The lessons drawn from past programs suggest the following design philosophy for the development of the next generation space transportation system: ${ }^{1 "}(1)$ technology-driven development, (2) short-term economical benefits, (3) growth potential, (4) 
achievable, and (5) safe and reliable, even at the expense of greater up-front cost and lower performance. The economical benefits are judged for commercialization of space transportation. By definition, a commercial venture is a low-risk investment and generates a 20 -plus-percent return per annum on investment with the investment payback (preferably) within 5 years. The design philosophy and economics requirement lead to a spaceplane concept based on two stages, to a spaceplane that operates like an aircraft, and to a spaceplane design with built-in growth potential.

Staging can increase performance of a given technology, reduce the vehicle sensitivity to performance parameter variations, or deliver equal performance and lower risk with less advanced technology. TSTO vehicles offer greater margin and have higher payload potential than SSTO vehicles. TSTO vehicles require smaller propellant mass fractions, resulting in lower take-off gross weight (TOGW) than SSTO vehicles. If vehicles with airbreathing propulsion are considered, the useful airbreathing corridor for TSTO vehicles is larger than that for SSTO vehicles, and first stages of a TSTO concept have potential for greater atmospheric-cruise capability than SSTO vehicles. The need for developing two stages is of a secondary consideration to the aforementioned design philosophy, economic requirement, and advantages over SSTO vehicles.

Orbital-mission flexibility and greatly enhanced operability are achievable, if spaceplanes have features that approach those of commercial aircraft. Airbreathing propulsion provides higher overall performance and far greater operability than that possible with rocket propulsion. Examples of enhanced operability are aircraft-like powered-landing operations, including go-around and vehicle intact-abort capability.

In addition to the aforementioned attributes, the full reusability of spaceplanes leads to significantly reduced operational costs, which in turn, reduce the life-cycle costs (a sum of development, acquisition, and operation costs) of a fleet of spaceplanes. If spaceplanes are designed with built-in growth, life-cycle costs are further reduced. The TSTO spaceplane, with airbreathing propulsion on the first stage, can fulfill the near-term access-to-space goals, while greatly reducing the cost, substantially improving mission flexibility, operability, safety, and reliability, and offering significant growth potentials and multiple avenues.

\section{TSTO Spaceplane Concept}

Figure 1 shows an artist's rendition of the TSTO spaceplane considered for the mission of achieving 220 nautical miles circular orbit at a $51.6^{\circ}$ inclination, with 25,000-lb payload [International Space Station Alpha (ISSA) resupply mission]. The genesis of this spaceplane is the Study of Advanced Air-breathing Launch Vehicles with Cruise Capability by Lockheed Company in 1967 for NASA Ames Research Center. ${ }^{11}$

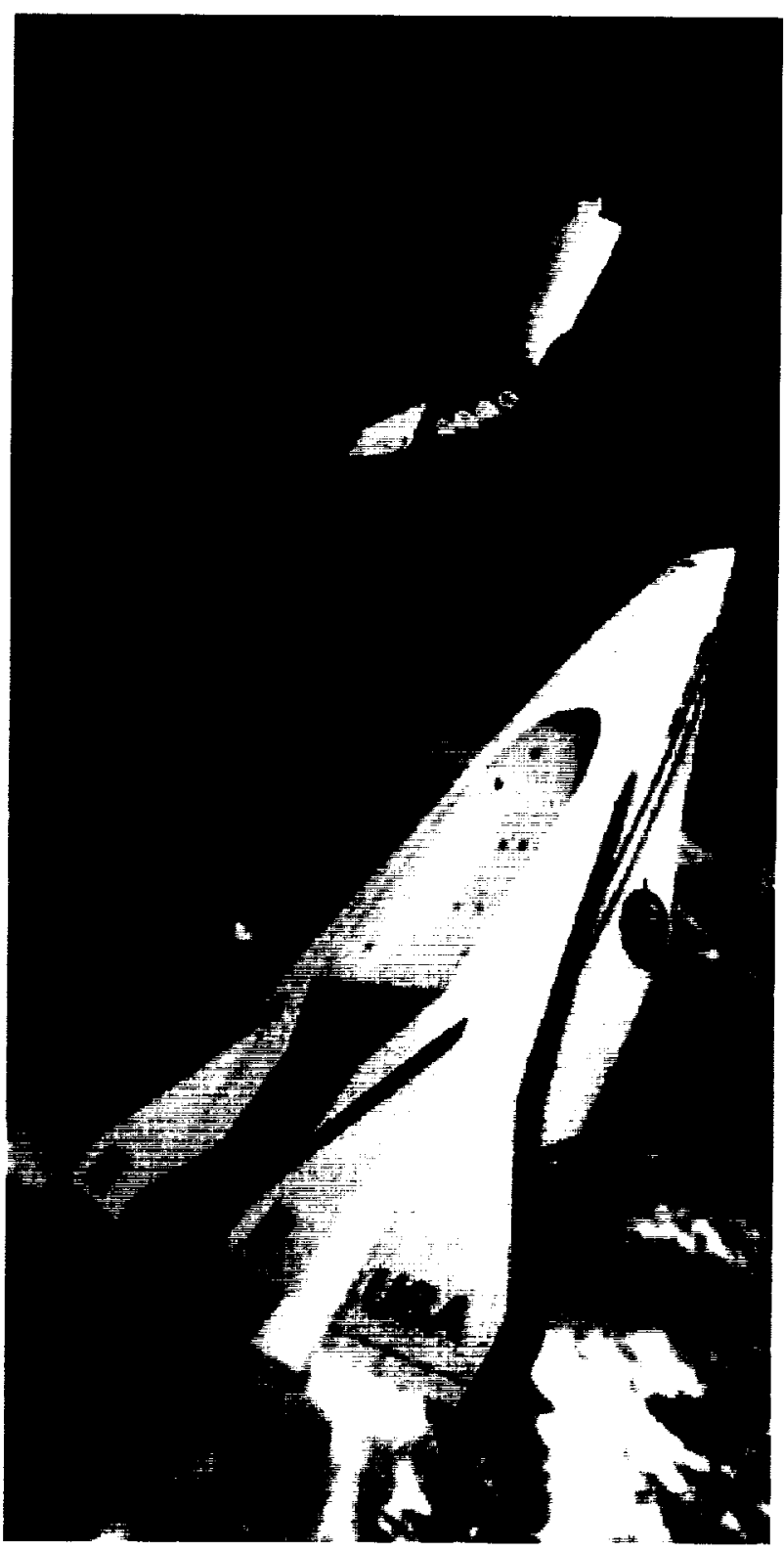

Figure 1. Artist's rendition of the TSTO spaceplane concept. ${ }^{8}$ 
Both the first stage (launcher) and second stage (orbiter) vehicles are lifting-body configurations. The orbiter is nestled within the outer mold line of the launcher. The cargo bay dimensions of the orbiter are $15 \times 15 \times 30 \mathrm{ft}$. The launcher propulsion system consists of a turbo/ram/scramjet propulsion system, including low- and high-speed air-breathing engines, while the orbiter propulsion system is a conventional liquid oxygen (LOX)/hydrogen rocket engine.

The structural concept for the launcher and orbiter is cold-structure, skin-stringer/frame-stiffened, integrallobed tanks (aluminum-lithium alloy for LOX tank and composite for hydrogen tank), with composite intertank structure. The external thermal protection system (TPS) consists of advanced ceramic tile/blanket systems. Both stages of the spaceplane are designed with 15-percent dry-weight margin.

Each stage of the spaceplane has a crew of two. The launcher takes off horizontally and both stages land horizontally, with the launcher making a powered landing. The take-off speed is limited to 300 knots. Staging is executed at low hypersonic Mach number $(5<\mathrm{M} \leq 12)$. The maximum axial acceleration during ascent is limited to $3.0 \mathrm{~g}$, and the normal load factor is limited to $2.5 \mathrm{~g}$.

After launching the orbiter, the launcher executes a decelerating 180-degree turn and cruises on the lowspeed air-breathing system back to the launch site. After separation, the orbiter continues to accelerate up to main engine cut-off (MECO), coasts to the target apogee, and circularizes at that altitude. The orbiter has an on-orbit $\Delta \mathrm{V}$ of $600 \mathrm{ft} / \mathrm{s}$. After completing the onorbit mission, the orbiter de-orbits, enters the atmosphere, decelerates aerodynamically while banking to meet cross-range requirements, and executes an unpowered landing at the launch base.

A study was conducted to determine the extent to which the orbiter is submerged within the launcher. Structural depth of the launcher in the payload region is traded for transonic drag increment of the mated combination. The lowest weight system resulted when the orbiter was fully submerged.

Hydrogen is the preferred fuel for the launcher for a number of reasons. First, hydrogen offers significant propulsion efficiency and thermal cooling capability over hydrocarbons, resulting in lower weights and costs. Second, the sizing of the hydrocarbon-powered launcher is principally determined by the size of the orbiter, whereas the size of the hydrogen-powered launcher is mainly determined by its fuel-fraction mission requirements. In the latter case, the possibility of forming hydrogen on-aboard from hydrocarbons and water is not considered. If it were considered, the onboard hydrogen generation ${ }^{12}$ would also impact the sizing of the launcher. Third, hydrocarbons limit the launcher performance growth. Fourth, the staging Mach number can be higher with hydrogen than with hydrocarbons. Finally, there is little risk-avoidance provided by hydrocarbons on the launcher if hydrogen is used on the orbiter.

Hydrogen-powered, after-burning turbojets were selected for the launcher low-speed propulsion system. Figure 2 conceptually shows the jet engines installed on the launcher, consisting of an over-and-under arrangement of turbojets and $\mathrm{ram} / \mathrm{scramjets.} \mathrm{As} \mathrm{a}$ function of flight Mach number, the inlet splitter plate position is set to provide the turbojet engine the required inlet mass flow. The turbojet engine sea-level thrust level is in the 70,000-pound class. Six turbojet engines are installed; they are used from Mach 0 to 2.4, including takeoff and transonic acceleration. The weight of the turbojet system includes bare engine weight, afterburner and nozzle weight, and the close-off door, resulting in an installed engine thrust-to-weight ratio of 6.65. The operating range of turbojet engines could be extended to Mach 3.5, with present, state-ofthe-art turbojet technology.

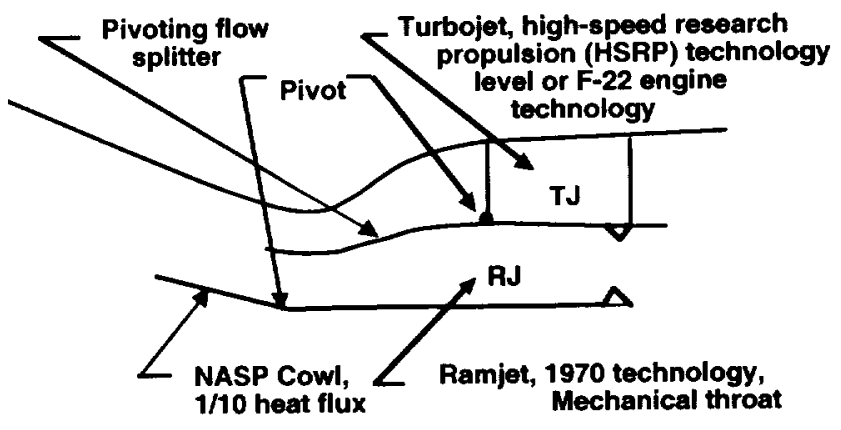

Figure 2. Jet engines installation. ${ }^{\circ}$

The ramjet is started at Mach 1.05, to cancel ram drag and internal friction, and operated to 6.0. From Mach 0.9 to 1.4 , base burning is used to reduce transonic nozzle drag. At the transonic pinch point, the resultant acceleration is $2.3 \mathrm{ft} / \mathrm{s}^{2}$. The reduced transonic specific impulse $\left(I_{s p}\right)$, shown in figure 3 , reflects the fuel consumed for base burning. Above Mach 6, the NASPderived, dual-mode, ram/scramjet engine technology is used. 
The orbiter propulsion system consists of main rocket engines and an integrated OMS/RCS system. The baseline OMS/RCS system is a liquid $\mathrm{H}_{2} / \mathrm{O}_{2}$-fueled system. The main rocket engines are expander cycle, $\mathrm{H}_{2} /$ LOX engines, based on RL-10 technology. The thrust class of the engine is approximately $150,000 \mathrm{lb}$, with an engine thrust-to-weight ratio of 54. It was well within 1993 technology limits and is similar to the Pratt and Whitney RL2000-study engine. Four engines are selected to provide abort-to-orbit capability from the launch point, if an engine is shut down. From Mach 5-launch condition, the orbiter can attain an orbit altitude of 65 nautical miles, which is sufficient to return to the launch site on the next orbital pass.

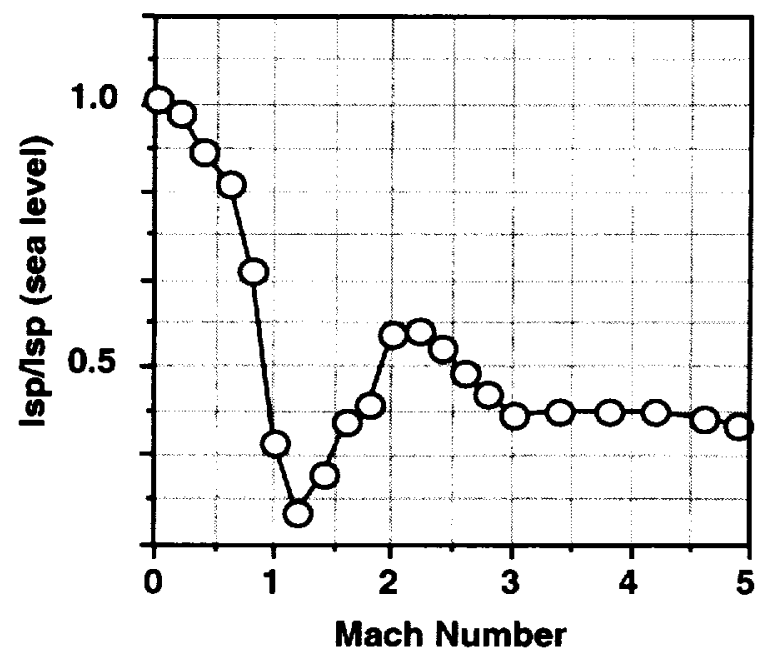

Figure 3. Launcher propulsion-specific impulse.

A low-pressure, expansion-cycle rocket engine is used due to its simple architecture, which would result in high operational reliability and maintainability, and in relatively low development and acquisition costs. In fact, the orbiter could use any of the advanced rocket engines, such as an advanced-staged, combustion-cycle engine, modular engines, aerospike engines, etc. The payload capabilities of the orbiter could be enhanced with these advanced, higher-performance, lower-weight engine systems.

\section{Analysis Method}

The ARC-developed hypersonic aerospace vehicle optimization code (HAVOC) for hypersonic vehicle synthesis is used to perform estimates of systems performance characteristics and design specifications (fig. 4). It uses engineering analysis methods to compute vehicle performance and design characteristics, including aero- and thermo-dynamics, propulsion, structures, trajectory, and system cost. In the design process, the synthesis code closes the design to meet mission performance requirements, matching vehicle weight and volume required to that available.

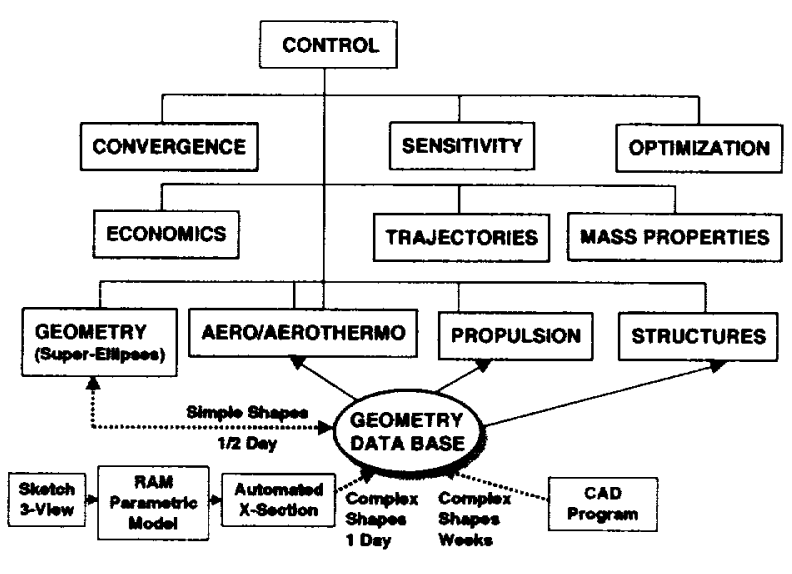

Figure 4. Hypersonic aerospace vehicle optimization code (HAVOC).

\section{Aero- and Thermo-Dynamics}

The subsonic and transonic aerodynamics for a given configuration are computed as functions of the free stream Mach number, angle-of-attack, and the gross geometric parameters of the body and wing (fig. 5). Experimental or high-fidelity computational results are used to calibrate the empirical methods in the lowspeed regime for the body, including the high-subsonic/ transonic/low-supersonic base drag model. In the supersonic/hypersonic speed range, the fuselage pressure and aerodynamic forces (lift and pressure drag) are computed using real-gas tangent-wedge/ tangent-cone, independent-panel methods. For the higher hypersonic Mach number regime, Newtonian methods are used to compute surface-pressure coefficients. Friction drag is computed using various reference enthalpy methods (e.g. Eckert or van Driest). The engine-off base drag is computed using empirical relations for the high-subsonic/transonic/lowsupersonic speed range, and estimated at higher Mach numbers assuming a 70-percent vacuum in the base region (i.e., $C p_{\text {base }}=-1 / M^{2}$ ).

Calculation of the aerothermal environment begins with the flight condition along the vehicle trajectory. With the flight condition specified (i.e., given the free-stream Mach number, the angle of attack, and the free-stream 
dynamic pressure), the boundary-layer edge conditions are computed for each panel. For acreage-heating calculations, the skin-friction coefficient is computed using reference enthalpy methods noted above.

Calculations of local skin friction and convective heat transfer film coefficient involve an iteration to balance the convective heat flux, the radiative heat flux, and the conductive heat flux into the vehicle. For vehicle designs with exterior insulation, the thermal energy conducted into the TPS is generally on the order of 5 percent of the total convective heating. Neglecting this relatively small conduction term in the surface energy balance results in a somewhat higher radiation equilibrium surface temperature, which is used as a design margin for the TPS. The reference Reynolds number is then computed using the boundary-layer edge velocity determined above and the running length for that panel location. The local skin-friction coefficients and local Stanton numbers are then calculated using the Reynolds analogy and the reference Prandtl number with the appropriate formulation, depending on laminar or turbulent flow conditions. Finally, the convective heating film coefficient is computed from the Stanton number, reference density, and edge velocity.

The local recovery enthalpy is determined using the edge static enthalpy, the edge velocity, and the edge Prandtl number, with the Prandtl number correction factor for laminar or fully turbulent flow, as appropriate. The convective heat-flux rate is then computed.
The radiative heat flux is computed by determining the emissivity as a function of TPS material distribution and the wall temperature. The iteration loop is repeated until surface energy balance is achieved.

For blunt, leading-edge heating calculations, a modified stagnation heating Faye-Ridell method ${ }^{13}$ is used. The hot-wall heating rate is computed for off-stagnation conditions using a modified Lee's method. ${ }^{14}$ The stagnation point is determined using a Newtonian model with the unit surface normal co-linear with the free-stream velocity vector. The actual wall temperature computed for stagnation regions, or acreage areas, will generally differ from the radiation equilibrium wall temperature computed above. This conducting wall temperature depends on the heating history along the trajectory. Up to the peak-heating point, heat is conducted into the TPS, and the resulting wall temperature will be lower than the nonconducting wall temperature. After peak heating, the TPS begins to reject heat, with the resulting conductive heat flux back to the surface resulting in a higher wall temperature than the nonconducting value.

\section{Propulsion}

For the rocket engine, a simplified performance model is used, with vacuum and sea-level-specific impulse as inputs, along with vacuum thrust. Altitude performance of the rocket is computed using ambient pressure corrections to $I_{s p}$.

\begin{tabular}{|c|c|c|c|c|}
\hline & SUBSONIC & TRANSONIC & SUPERSONIC & HYPERSONIC \\
\hline LIFT & & & & \\
\hline - BODY & \multicolumn{2}{|c|}{ Empirical f (AR, Mach) } & \multicolumn{2}{|c|}{$\begin{array}{c}\text { Tangent Wedge/Tangent Cone } \\
\text { Newtonian Mach }>18\end{array}$} \\
\hline$-W I N G$ & \multicolumn{2}{|c|}{ Low AR Theory } & \multicolumn{2}{|c|}{ Linearized Supersonic } \\
\hline \multicolumn{5}{|l|}{$\frac{1}{\text { DRAG }}$} \\
\hline - INDUCED & \multicolumn{2}{|c|}{ Empirical $f$ (Mach) } & \multicolumn{2}{|c|}{$\begin{array}{l}\text { Tangent Wedge/Tangent Cone } \\
\text { Newtonian Mach }>18\end{array}$} \\
\hline - SKIN FRICTION & \multicolumn{2}{|r|}{ Schlichting } & \multicolumn{2}{|c|}{$\begin{array}{c}\text { Reference Enthalpy } \\
\text { Eckert, Van Driest, Schlichting } \\
\text { ReTheta/M (Transition Criteria) }\end{array}$} \\
\hline - BODY WAVE & 0 & $\begin{array}{c}\text { Empirical } \\
f \text { (mean sweep, FR, Mach) }\end{array}$ & \multicolumn{2}{|c|}{$\begin{array}{l}\text { Tangent Wedge/Tangent Cone } \\
\text { Newtonian Mach }>18\end{array}$} \\
\hline - WING WAVE & \multirow[t]{2}{*}{0} & $\begin{array}{c}\text { Empirical } \\
f(\text { sweep, } T / C) \\
\end{array}$ & \multicolumn{2}{|c|}{ Prandtl Meyer Shock Expansion } \\
\hline - BLUNTNESS & & 0 & \multicolumn{2}{|c|}{ LE Radius/Sweep \& Newtonian } \\
\hline - BASE & \multicolumn{2}{|c|}{ Empirical f (Mach) } & \multicolumn{2}{|c|}{$70 \%$ Vacuum } \\
\hline
\end{tabular}

Figure 5. HAVOC aerodynamics. 
For the ramjet, dual-mode and scramjet operation, a nose-to-tail propulsion model uses the keel-line geometry and quasi-one dimensional area distribution of the combustor to compute the propulsion flow field. This nose-to-tail propulsion model consists of a planar inviscid 2-D real-gas, weak-wave flow code, coupled to a 1-D subsonic/supersonic combustor analysis code, to predict nose-to-tail flow-path characteristics. The forebody boundary layer is computed using the inviscid solution to provide edge conditions. Shear forces and heat transfer are computed for the forebody/inlet using reference enthalpy methods. Inlet unstart and self-start boundaries are computed using computed flow-field properties at the cowl-lip plane, and one-dimensional isentropic flow between the cowl-lip and inlet throat.

Beginning at the inlet throat, the 1-D combustor mass, momentum, and energy equations with wall-skin friction and heat transfer are solved (stepwise) through the cumbustor. Multiple fuel-injector stations and preburning are provided for. Combustor efficiency (i.e., heat-release schedule) is computed as a function of injector Mach number and injection angle, local equivalence ratio, and axial distance from injector station. Overall engine heat balance is computed using an input combustor, skin-friction coefficient as a function of free-stream Mach number.

In dual-mode operation, normal shock and thermal choke plane locations are also computed. The nozzle flow field is then computed from the combustor exit solution using the real-gas, weak-wave 2-D code, which includes nozzle and cowl flap geometry. Equilibrium or frozen flow is computed in the nozzle region using the mole fraction array at the combustor exit plane. Firstorder estimates of axial and normal forces and of pitching moments are computed as a function of vehicle geometry and flight conditions. Overall propulsion system heat loads are then used to determine fuel inlet total temperature or to compute required engine-cooling equivalence ratio.

\section{Trajectory}

A 3-degree-of-freedom model is used to compute flight trajectory, using the equations of motion of a pointmass aircraft moving relative to a rotating, spherical earth. The trajectory flight path is computed using one of two methods. ${ }^{15}$ First, an energy-state approximation is used, coupled to an input schedule of Mach number versus altitude. The second method is to specify a set of control variables (consisting of angle-of-attack, bank angle, throttle setting, and gimbal angle), and then to solve the equations of motion, using a first-order Euler integration (subject to a set of flight-path constraints, including maximum load factor and/or surfacetemperature limits at a specified body location). For either modeling methods, the trajectory can be computed untrimmed or trimmed in pitch.

\section{Structural and TPS Weights}

As part of the aircraft structural weight, the items estimated are: shell, walls, frames, tension ties, spanwise beam, nonoptimum, and tank. The nonoptimum weight accounts for non-calculable weight items, such as fasteners, welds, cutout reinforcement, surface attachments, nonuniform gage requirements, and manufacturing constraints, and is a percentage of the previous five weight items.

The tank item is an estimate of the weight of a discrete tank or of bulkheads and other items necessary to convert the body structure into an integral fuel tank. An option for noncircular vehicles is an integral, pillowtank arrangement in which intersecting circular shells are fitted within the vehicle outer mold line.

The body-structural-weight-estimation method in the HAVOC is based on one-dimensional-beam theory structural analysis, resulting in a weight estimate that is directly driven by material properties, load conditions, and vehicle size and shape, and is not confined to an existing database. Since the analysis is done station-bystation, along the vehicle longitudinal axis, the distribution of loads and vehicle geometry is accounted for, providing an integrated weight that accounts for local conditions.

The analysis begins with calculation of vehicle loads. Three types of loads are considered-longitudinal acceleration, tank pressure, and bending moment. Four loading cases are computed-power-on/tanks full, power-off/tanks full (abort condition), power-on/tanks empty (MECO condition), and power-off/tanks empty (entry condition).

It is assumed that structural materials exhibit elastoplastic behavior. The values of properties used are a reduced percentage of published, minimum values to account for such effects as fatigue, stress corrosion, creep, and thermal cycling; and thermal stresses that are not modeled as cold structures are considered.

The body weight analysis described above has been extensively correlated. It has been applied to existing aircraft for the purpose of determining the nonoptimum portion of structural weight. It has also been compared 
with many other analyses of hypersonic aircraft. For example, it was applied to the designs developed by the five prime contractors for the first aircraft concept downselect in the NASP program, and agreement was found to be generally excellent.

Estimation of TPS weight is based on transient, onedimensional heat-conduction analysis. The aerothermal environments are computed as a function of time along the flight trajectory, including the recovery enthalpy, the enthalpy-based convective film heat transfer coefficient, and the local surface pressure for each surface panel. The one-dimensional materials stackup is specified for each body point, with associated internal boundary conditions (e.g., internal gas bulk temperature and film coefficient), and internal radiation gap conditions input as function of time. Soak-out boundary conditions are also specified. Material thermoproperties are specified as a function of temperature and pressure (if applicable). The energy balance at the exterior surface is computed using a temperaturedependent emissivity for the corresponding TPS material. The TPS sizing process then consists of iterating on the required insulation thickness until all interior bond-line temperature constraints are satisfied. Minimum-gauge TPS thickness constraints are also imposed.

The weight and volume of the vehicle subsystems are computed using correlation equations developed for space-launch and hyper-velocity vehicles. Correlation parameters typically used related to overall vehicle gross or empty weight, vehicle size, and mission-related requirements. Correction factors for each subsystem element are made available to match a specifically known subsystem component weight. The accounted subsystem elements are: flight controls and actuation (electrical, hydraulic and pneumatic), power generation and distribution, environment and life-support, thermal control, and propulsion-feed systems.

\section{Life-Cycle Costs}

The life-cycle cost (LCC) is based on airframe and engine development, vehicle acquisition, and operational costs. Cost-estimating relations are based on previous airplane programs, and these relations are supplemented, when necessary, to account for the fact that spaceplanes approach, rather than actually have, aircraft-like operation. The following databases were used: B-727, B-737, B-747, and B-757 (modified with those for X-15 and XB-70), engine (HyFAC Report ${ }^{16}$ ), launch vehicles (other than the Space Shuttle), and operations (airline-like). Dry weights and vehicle speed are largely used for estimating development and acquisition costs. In the final analysis, the total cost of space operations (including procuring and launching a spacecraft) must be reduced.

Note that the cost-estimating relations for new vehicles, based on new technologies and new operating procedures, are likely to produce large uncertainties in the estimated costs. However, the same cost-estimating relations are used for all vehicles. The relative differences are, therefore, much less uncertain than the absolute costs.

\section{Hot Versus Cold Structures}

The launcher is modeled using 20 structural sections, with skins, stringers, and frames sized for bending, axial, and pressure loads. Insulation thickness is sized for 16 zones, consisting of 20 perimeter points at 20 cross-sectional stations. Lobed tanks (fig. 6) are also designed for bending, axial, and pressure loads.

Liquid hydrogen tanks are integral tanks having intersecting lohes. These tanks are made of graphite/epoxy structure with Z-stiffeners, and with external Rohacell foam structure attached using polyurethane glue (fig. 7). Toughened, unipiece fibrous insulation (TUFI) ceramic tiles are attached to the Rohacell foam tiles using RTV glue and a Kapton vapor barrier. Liquid oxygen tanks on the orbiter are Z-stiffened, aluminum-lithium tanks, with a similar TPS. The leading edges of the spaceplane have the same TPS as those assumed for the X-30 spaceplane. Engine surface unit weights and seals, and systems weights are also derived from those for X-30.

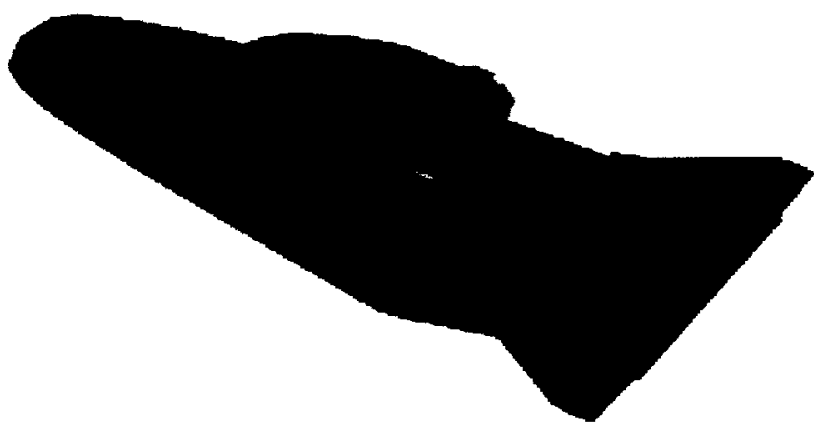

Figure 6. Integral tanks. 


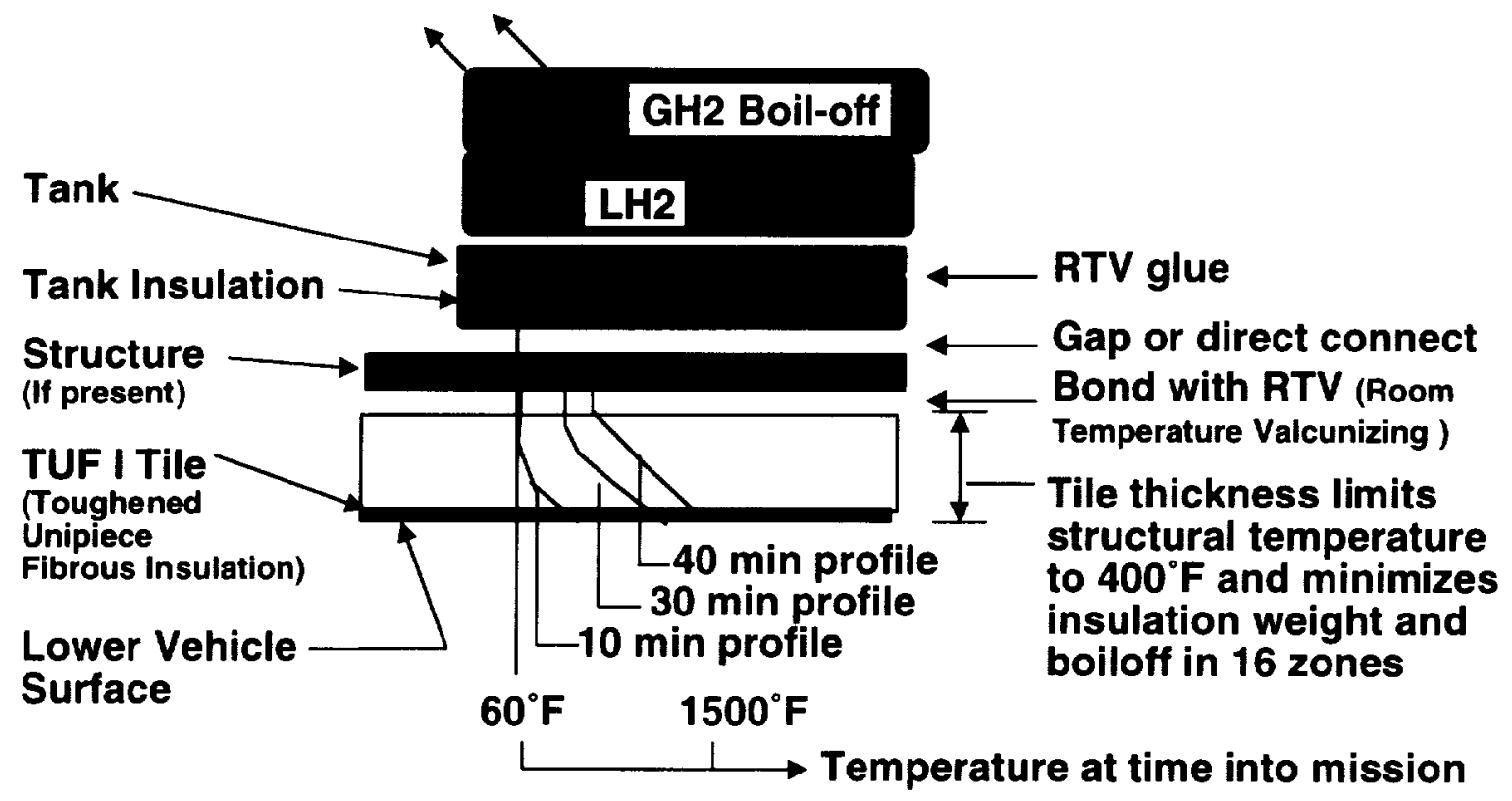

Figure 7. Thermal protection system (TPS).

Extensive development efforts during the 1960s through the 1980s on integrated thermal structures (e.g., with TMC aeroshell), resulting in hot structures, have not demonstrated an advantage over cool structures, with external insulation, in terms of safety, robustness, risk reduction, and simplicity. Hot structures are heavy, complex, and expensive, particularly when they are actively cooled.

Systems analyses for the launcher with Mach 5 staging and 25,000-lb payload indicate that the best structural approach for lightweight spaceplanes is using external TPS on a cool structure (figs. 8 and 9). For these analyses, structures are constructed using graphite/ epoxy $(\mathrm{G} / \mathrm{E})$ or aluminum alloys, and the external insulation of these structures is tailorable advanced blanket insulation (TABI) or TUFI. Cold, integral-tank structures are 23 percent lighter than hot-shell structures for hypersonic cruisers. ${ }^{17}$ The research, technology, development, and evaluation (RTD\&E) cost estimates for $\mathrm{G} / \mathrm{E}$ structures with external insulation are significantly lower than the cost estimates for hot structures (fig. 10).

The external insulation design for spaceplane is lighter than those based on hot structures because of: (1) structures with low peak temperatures utilize more efficient and less expensive materials, (2) when the insulation is placed outside a structure, the usable volume of the structure increases, (3) the TPS is less complicated, and (4) insulation of cryogenic tanks leads to a fewer requirements on TPS.

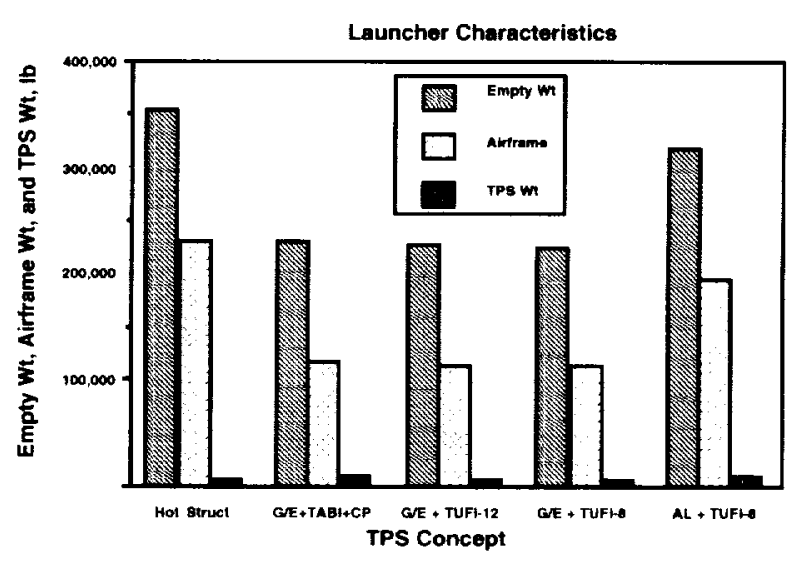

Figure 8. A comparison of system weights for different TPS concepts.

Installation of ceramic TPS on a cool structure, in turn, does impose design and integration issues on the airframe, including allowable strain constraints on the substructure for direct bond, requirement for launcher panels in nonconformal tank regions, and surface shear and vibro-acoustic limitations associated with blankets. Standoff metallic TPS present integration issues, in terms of support structure, lower temperature limits. 
face-sheet temperature gradient and thermal stress, and creep limitations. Ceramic systems are generally lighter than metallic TPS as a result of relatively high attachment unit weight for metallic concepts, the latter becoming lighter only for high-integrated heat loads when expensive, lightweight multilayer insulation is used. Metallic TP systems require coatings, which if damaged lead to chemical reactions at the metallic surface and to a catastrophic failure.

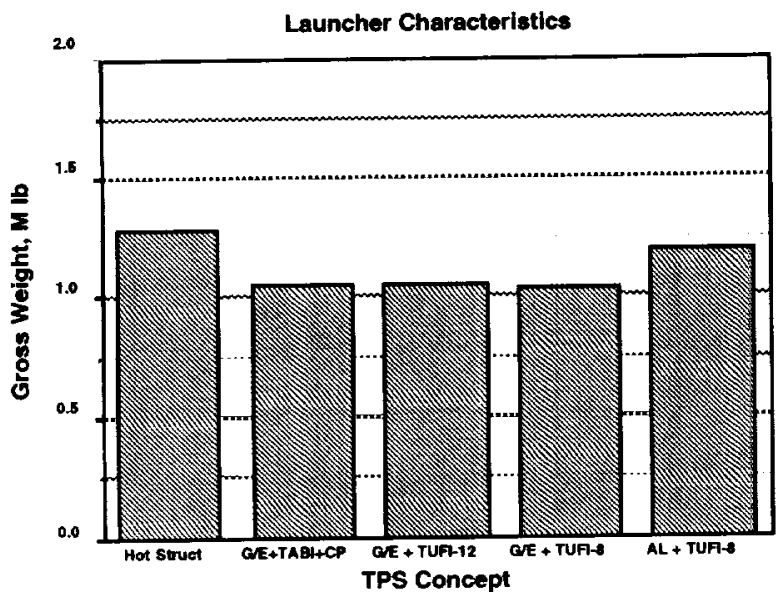

Figure 9. A comparison of take-off gross weights with different TPS concepts.

The X-33 was designed with cold structures. It has load-carrying tanks and an external, leeward aeroshell and windward frame structure that supports the metallic, standoff TPS, and transmits aerodynamic loads into the primary structure. The proposed TSTO spaceplane has directly bonded TPS.

\section{Optimum Staging Mach Number}

A study is being conducted to assess the impact of the staging Mach number on the size, weight, performance, and life-cycle cost of the proposed TSTO spaceplane. The LCC is the least, if the staging Mach number is approximately Mach 10, as discussed below.

As the staging Mach number is increased, the weight of the TPS increases on the launcher, increasing significantly above Mach 10 (fig. 11), due to high, convective heat loads associated with high-Mach and high-dynamic pressure-flight conditions. Likewise, the TPS fractions for the orbiter increase (but only slightly), as it is carried on the launcher and entry heat loads primarily determine TPS weights. Apart from the harsher thermal environment at higher flight speeds, the size of the launcher slightly increases, with increasing fuel fractions, as the staging Mach number is increased. Empty weights of both stages decrease as the staging Mach number is increased, until Mach 12 (fig. 12). Beyond Mach 12, the empty weight of the launcher increases, driven by the increased TPS weight and the increased structural weight as a result of higher, required mission-fuel fractions.

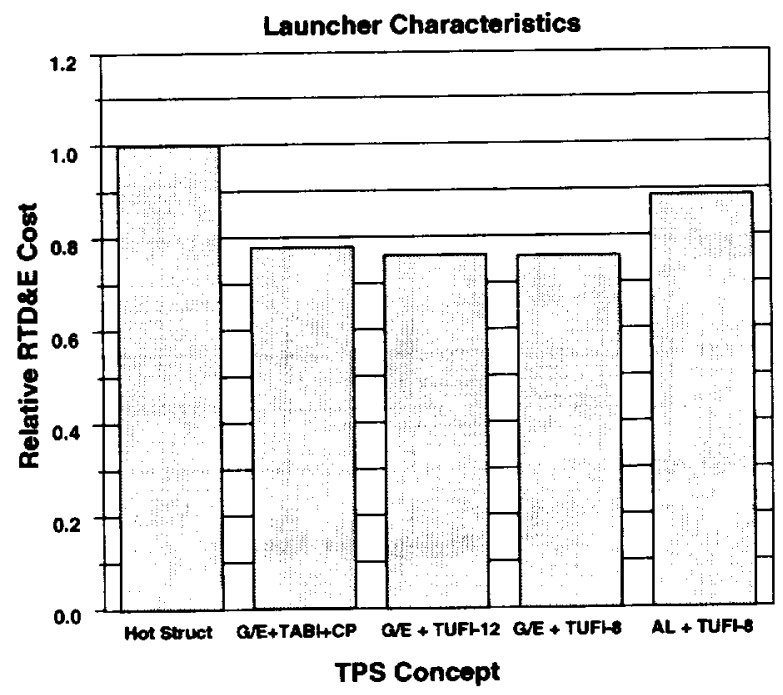

Figure 10. A comparison of RTD\&E costs for different TPS concepts.

As the staging Mach number is increased, the TOGW, which is the takeoff gross weight of the launcher, decreases until Mach 12 (fig. 13). The orbiter weight decreases as less fuel and oxygen are required for achieving reduced velocity increment to reach orbit with the higher staging Mach number. The launcher has to carry a lighter obiter, resulting in lower structural weights for the launcher as the fuselage bending moments are reduced. Thus, the total system weight is reduced for the same payload or the payload weight is increased for the same system weight, while the basic physical characteristics of the spaceplane remains the same as the staging Mach number is increased from 5 to 12 .

When the Mach number is greater than 12, the required engine-equivalence ratio increases above the stoichiometric value to meet engine-cooling requirements, with an associated reduction in the engine-cycle, specific impulse. This leads to higher mission-fuel fractions and, hence, higher closure gross weights. Finally, staging at a higher Mach number increases the downrange staging point, resulting in a 
longer cruise return to launch-site range requirement. This further increases the required mission fuel fraction, and pushes the vehicle closure point to higher gross and empty weight values.

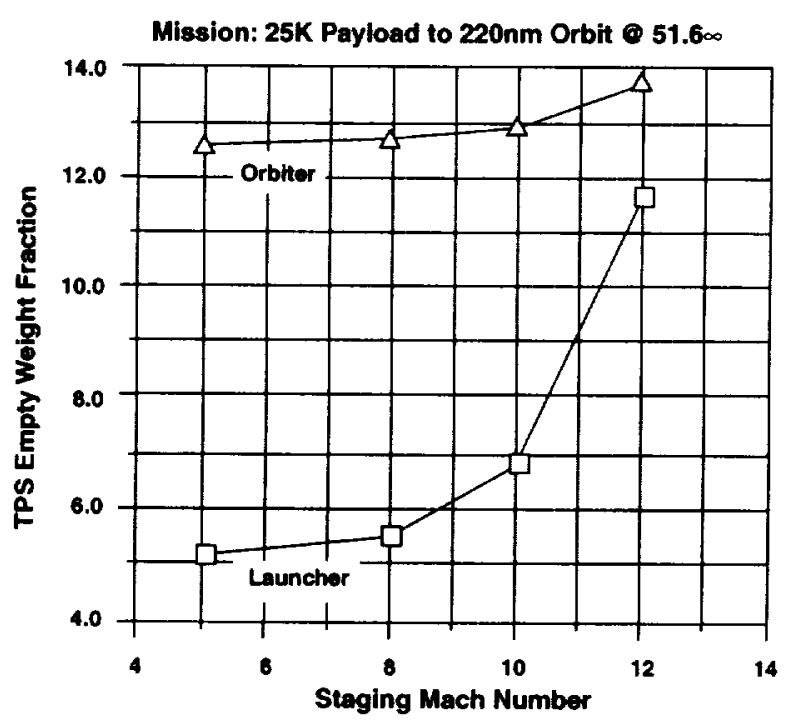

Figure 11. Sensitivity of TPS weights to staging Mach number.

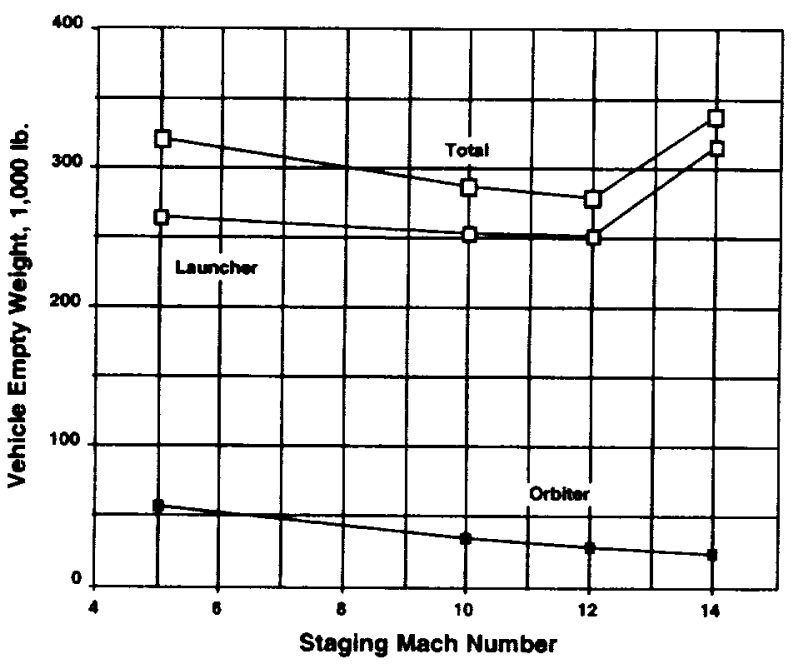

Figure 12. Sensitivity of vehicle empty weight to staging Mach number.

The RTD\&E costs are driven primarily by subsystem weight or, in the case of the airframe RTD\&E costs, by a dry weight-speed product. The acquisition cost is primarily determined by dry weights, and operational costs are largely determined by maintenance and propellant costs. Maintenance costs are primarily a function of subsystem dry weight and vehicle surface area.

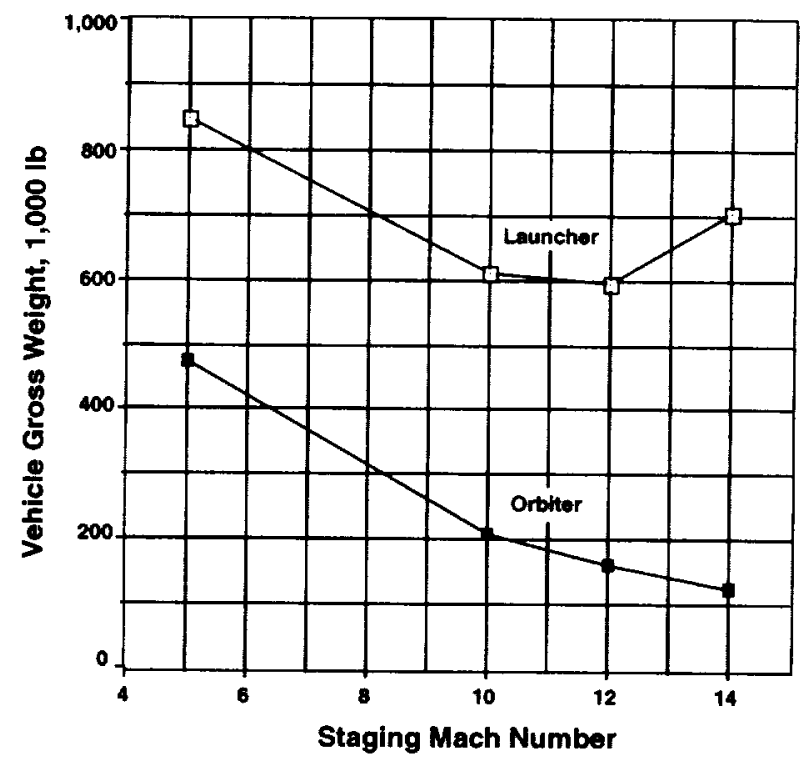

Figure 13. Sensitivity of TOGW to staging Mach number.

Figure 14 shows that the LCC decreases as the staging Mach number is increased, from Mach 5 to 10 . From Mach 10 to 12, RTD\&E costs of the launcher offset the reduced empty weight trend, resulting in increasing LCC. The cost of RTD\&E and acquisition of scramjet engines, operating above Mach 10, increases. Existing ground-test facilities, and test techniques and subscale flight tests, such as those planned for $X-43$, are inadequate for developing scramjet engines above Mach 8. New test facilities and techniques, and flight tests with scramjet engines approaching those on spaceplanes, are required. ${ }^{10}$

Figure 15 shows the general configuration layout and dimensions of the spaceplane for Mach 10 staging. Table 1 presents some details of mass properties for the launcher and the orbiter for Mach 5 and 10 staging conditions. For the launcher, the weights for the horizontal and vertical tails and for their TPS are bookkept under control surfaces. The payload for the launcher consists of the full-up orbiter launch weight, plus integration/separation-system increment. The takeoff thrust-to-weight of the Mach 5 launcher is 0.516 . 


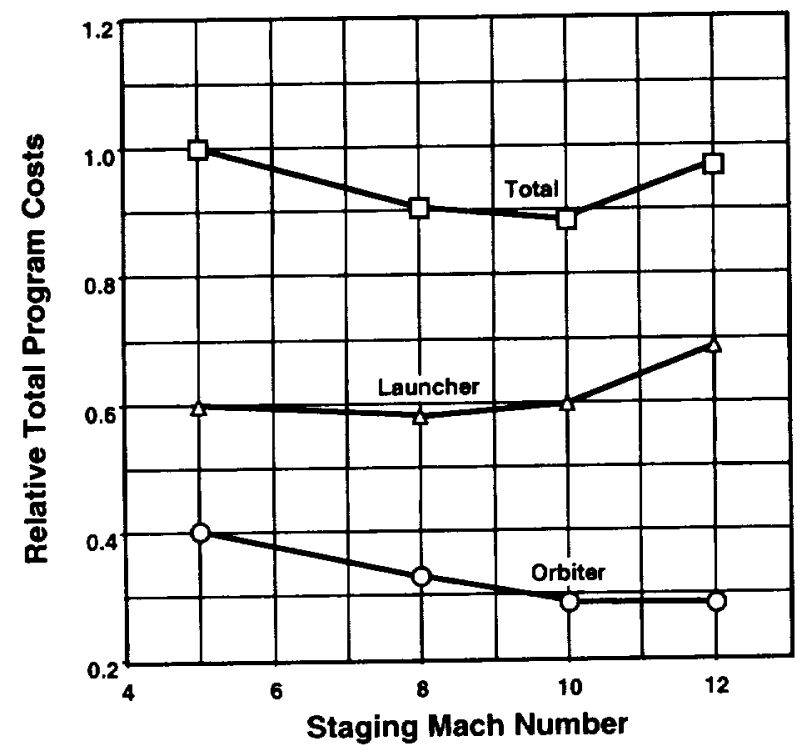

Figure 14. Sensitivity of LCC to staging Mach number.

The trends presented in figures 11 through 13 would be the same, even if some system weights were computed differently. For example, the landing gear weight is assumed to be approximately 1.5 percent of the TOGW. If this weight were to be 2.0 percent of the TOGW, the trends observed in these figures would not change.

\section{A Prototype/Experimental Spaceplane with Built-in Growth}

A TSTO spaceplane with Mach 5 staging offers lower performance at lower risk (because it avoids a scramjet), while that with Mach 10 staging offers higher performance at moderate risk (with a scramjet). Essentially, the same airframes can be used for staging from Mach 5 through 10, with modest TPS weight difference.

A basic design of a Mach 5 staging launcher is slightly modified to stage the orbiter at higher Mach numbers, or a launcher designed to stage at Mach 10 is used for launching the orbiter at lower Mach numbers. Likewise, an orbiter designed to stage at Mach 5 is slightly modified to stage at higher Mach numbers, or it is designed to stage at Mach 10, and used for staging at lower Mach numbers. Different combinations of the launcher and orbiter will lead to different payload launch capabilities. The combination giving the lowest LCC and highest growth potential requiring the least modifications is the one developed.
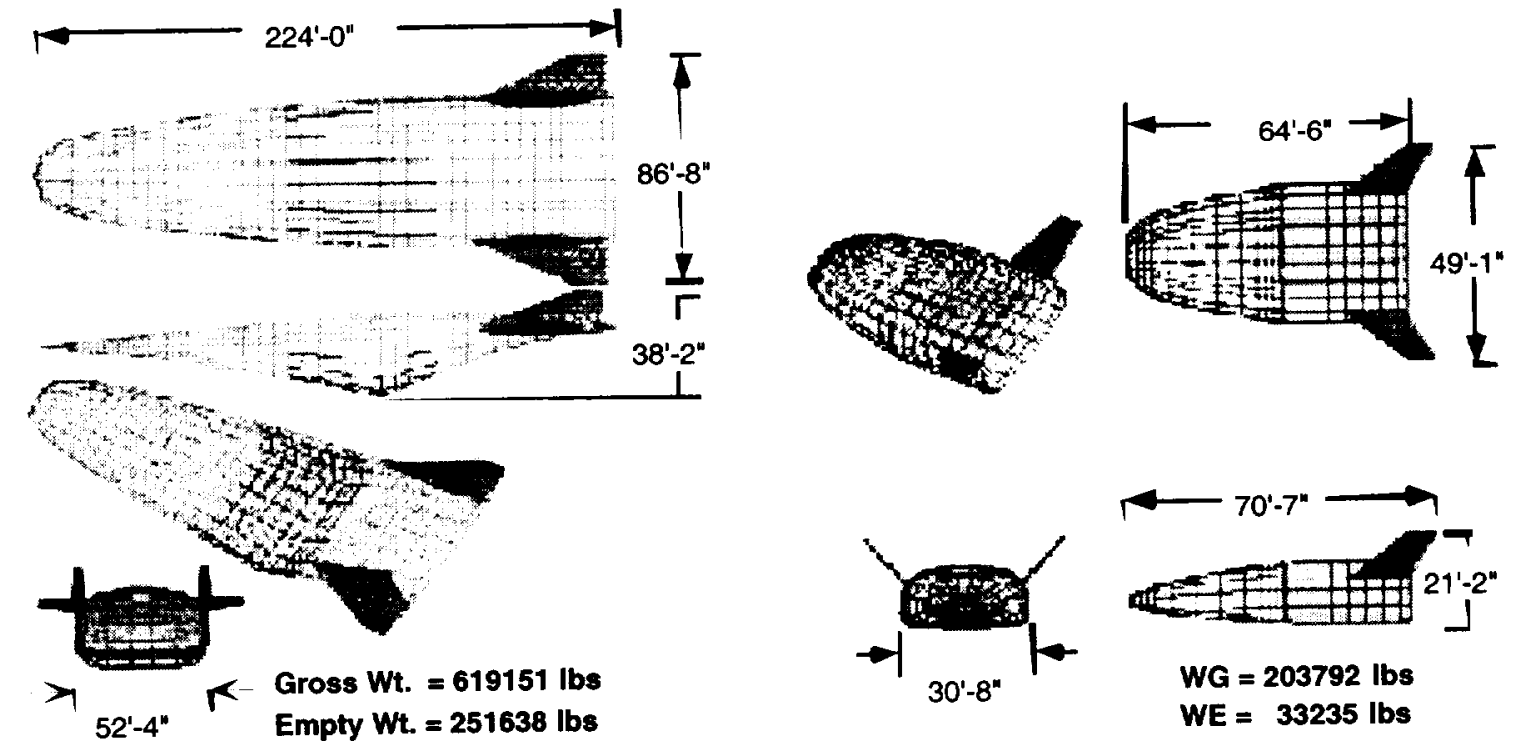

$W G=203792$ lbs

$W E=33235 \mathrm{lbs}$

Figure 15. TSTO spaceplane, $M_{S t}=10:$ launcher and orbiter. 
Table 1. Mass properties for Mach 5 and Mach 10 spaceplanes.

\begin{tabular}{|c|c|c|c|c|}
\hline \multirow[b]{2}{*}{ Item } & \multicolumn{2}{|c|}{ Mach 5 Staging } & \multicolumn{2}{|c|}{ Mach 10 Staging } \\
\hline & Launcher, lb & Orbiter, lb & Launcher, lb & Orbiter, lb \\
\hline $\begin{array}{l}\text { Airframe } \\
\text { Wing and TPS } \\
\text { Fuselage } \\
\text { Fuselage TPS } \\
\text { Control Surfaces } \\
\text { Landing Gear } \\
\text { Propulsion } \\
\text { Ramjets } \\
\text { Rockets } \\
\text { Turbojets } \\
\text { Inlets } \\
\text { Fuel Systems } \\
\text { Fixed Equipment } \\
\text { Empty Weight } \\
\text { Consumables } \\
\text { Propellant } \\
\text { Payload } \\
\text { Gross Weight } \\
\end{array}$ & $\begin{array}{r}113,695 \\
0 \\
68,264 \\
15,271 \\
15,842 \\
11,943 \\
133,914 \\
41,563 \\
0 \\
69,181 \\
14,748 \\
8,233 \\
17,269 \\
264,879 \\
1,176 \\
102,331 \\
476,490 \\
848,846 \\
\end{array}$ & $\begin{array}{r}30,203 \\
1,652 \\
12,545 \\
8,371 \\
4,810 \\
3,322 \\
17,011 \\
0 \\
12,088 \\
0 \\
0 \\
4,924 \\
9,689 \\
57,403 \\
1,920 \\
389,114 \\
25,000 \\
474,168 \\
\end{array}$ & $\begin{array}{r}110,984 \\
0 \\
65,769 \\
18,103 \\
17,059 \\
10,052 \\
125,858 \\
39,179 \\
0 \\
65,175 \\
13,828 \\
7,675 \\
14,405 \\
251,638 \\
1,759 \\
157,840 \\
204,813 \\
619,151 \\
\end{array}$ & $\begin{array}{r}18,832 \\
621 \\
7,588 \\
5,621 \\
3,758 \\
1,816 \\
9,296 \\
0 \\
6,605 \\
0 \\
0 \\
2,691 \\
4,535 \\
33,235 \\
1,954 \\
143,603 \\
25,000 \\
203,792 \\
\end{array}$ \\
\hline
\end{tabular}

As discussed in reference 10, the development of scramjet propulsion requires tests of engines that are to be used on spaceplanes, in the absence of at least two (preferably three) appreciably different size subscale engine tests.

The principal scramjet development challenge is in the Mach 10 to $23+$ range. Development of a prototype spaceplane leading to a fleet of operational vehicles requires: (1) a demonstration of net scramjet thrust across the complete air-breathing hypersonic Mach number range of interest, (2) validation of simulation models and verification of simulation-design tools, and (3) verification in an actual vehicle of the technologies and systems required for such vehicles.

These observations suggest the following programmatic philosophy: ${ }^{10}$ First, a TSTO spaceplane is designed for Mach 10 staging to orbit with at least a $25,000-\mathrm{lb}$ payload to the design orbit $\left(51.6^{\circ}\right.$ and $220 \mathrm{n}$. mi.). Second, the spaceplane is used for space access by staging at Mach 6. (The reason for choosing Mach 6 rather than Mach 5 for staging is explained later in this section.) Third, a fully reusable rocket propulsion system is developed. Fourth, the launcher is used for demonstrating scramjet operations from Mach 6+ to 10 . Fifth, once the scramjet is perfected to the level necessary and made operational, the spaceplane is used for space access by staging at Mach 10. Sixth, further development of scramjet technology at higher Mach numbers is conducted on a new, developmental second stage.

Following this philosophy, a P/X TSTO spaceplane is recommended as a means of providing access to space, for developing the operational hypersonic air-breathing propulsion system, and for developing fully reusable rocket-propulsion system, with significantly improved mass fraction and margin. ${ }^{10}$ Note that an aircraft may be a fighter aircraft and at the same time be an attack aircraft, e.g., F/A-18. In principle, the same plane may be a prototype plane and an experimental plane, and could be called a growth plane.

Three orbiters are developed (table 2). The launcher and the orbiters are reusable, piloted, and takeoff and land horizontally. The airframe and the turbo/ramjet on the launcher are fully reusable; the orbiter has fully reusable airframe and has low-maintenance rocket engines.

The launcher is initially designed to achieve Mach 10 . For example, the design of the launcher would include the TPS thickness distribution required to accommodate heat loads associated with Mach 10 operation and fuel tank capacity for the Mach 10 mission. The launcher airframe is a prototype. The launcher has a prototype propulsion system to achieve Mach 6 and has a 
demonstrator/experimental, dual-mode ram/scramjet engine from Mach $6+$ to 10 . The flow path of the experimental dual-mode ram/scramjet is the same as that for the prototype ramjet. The upper Mach 10 limit for the launcher is selected considering the staging Mach number trade study.

Table 2. Characteristics of TSTO P/X spaceplane.

\begin{tabular}{|l|l|l|c|}
\hline Vehicle & $\begin{array}{c}\text { Mach } \\
\text { Range }\end{array}$ & \multicolumn{1}{|c|}{ Propulsion } & Airframe \\
\hline Launcher & $\begin{array}{l}0 \text { to } 6 \\
6+\text { to } 10\end{array}$ & $\begin{array}{l}\text { Turbo/ram }(\mathrm{P}) \\
\text { Ram/scramjet (X) }\end{array}$ & $\mathrm{P}$ \\
Orbiter-R & 6 to orbit & Rocket $(\mathrm{P})$ & $\mathrm{P}$ \\
Orbiter-E & 9 to 24 & Rocket $(\mathrm{O}) /$ Scramjet $(\mathrm{X})$ & $\mathrm{P}$ \\
Orbiter-A & 9 to orbit & Scramjet(P)/Rocket $(\mathrm{O})$ & $\mathrm{P}$ \\
\hline
\end{tabular}

P: PROTOTYPE, X: EXPERIMENTAL, AND O: OPERATIONAL

After an operational scramjet that can perform up to Mach 10 is developed, a block change of the prototype Mach 6 propulsion system and experimental Mach 10 engine to a prototype Mach 10, air-breathing propulsion system leads to a prototype launcher for Mach 10 staging.

The three orbiters are: (1) orbiter- $\mathrm{R}$ with an all-rocket propulsion cycle, (2) orbiter-E with a rocket/airbreathing propulsion system, and (3) orbiter-A with an air-breathing/rocket system. Orbiter- $R$ is a prototype vehicle, designed to go to orbit. Orbiter-E and orbiter-A are discussed later on.

Initially, orbiter- $R$ is staged at Mach 6, because staging at Mach 6 reduces LCC from that for Mach 5 staging, while requiring little increase in the technology level for the launcher. The value of initial staging Mach number is chosen low to build-in payload growth to Mach 10, with the same launcher and the same orbiter-R.

The tanks on orbiter- $R$ are sized for a Mach 6 launch. Consequently, orbiter-R would have excess propellant volume when launched at Mach 10, and may achieve higher altitude orbits than the design orbit with lighter payloads. At higher staging speeds, the tanks are partially filled for achieving design orbit, so that the eliminated propellant load is replaced by additional payload weight within the existing payload bay. Additionally, payloads with larger size could be accommodated by rearrangement of the internal propellant tank configuration.

Table 3 presents mass properties for the launcher designed to stage the orbiter at Mach 10, but initially stages the orbiter at Mach 6, and for the orbiter. The Mach 6 staged orbiter is capable of carrying a 8,000-1b payload.

Strategically, the next-generation transportation system should be put into service as soon as possible, even though, initially, it would transport payloads much lighter than $25,000 \mathrm{lb}$. If, during the initial operations of this commonality spaceplane (with extra margins in the design and launching lightweight payloads), RTD\&E are undertaken in flight, an early IOC can be achieved. As discussed later, the time saved in achieving early IOC saves billions of dollars in total launch costs.

The launcher and orbiter- $R$ can be developed with a high level of confidence, since vast amounts of data, information, and knowledge are available from lowspeed systems, ramjet systems, the space shuttle orbiter, the NASP program, and other atmospheric-entry vehicles. Although the space shuttle main engine (SSME) requires a major maintenance/overhaul after approximately four missions, data, information, and knowledge are available for building low-maintenance rocket engines that can be reused for approximately 15 missions without a major maintenance. (A few Russian rocket engines are claimed to achieve majormaintenance-free operations equivalent to approximately 10 missions.) The development of rocket engines that can be reused for approximately $\mathbf{5 0}$ missions, without major maintenance, will require technology efforts.

As discussed in reference 9, relevant technologies for all subsystems are low-risk technologies. For example, the ramjet was successfully ground tested to simulated Mach 8 conditions in the 1960 s.

Because a significant portion of the evidence for establishing the credibility of the design would be direct evidence, the level of confidence in the design of the launcher would be quite high, to speeds of approximately Mach 6 . The quantity of this type of evidence would decrease and the level of indirect 
evidence would increase, as Mach 10 is approached. Also, the level of confidence in the design of orbiter- $R$, with major-maintenance-free rocket engines for approximately 15 missions, would be high.

Table 3. Mass properties for Mach 6 launch.

\begin{tabular}{|c|c|c|}
\hline & Launcher & Orbiter \\
\hline Item & $M_{s t}=10, l b$ & $M_{s t}=6,1 b$ \\
\hline Airframe & 95,455 & 17,271 \\
\hline Wing and Tail & 13,725 & 2,732 \\
\hline Fuselage & 55,124 & 7.263 \\
\hline Fuselage TPS & 15,700 & 5,046 \\
\hline Control Surfaces & 2,448 & 819 \\
\hline Landing Gear & 8,458 & 1,401 \\
\hline Propulsion & 126,477 & 7,174 \\
\hline Scramjets & 54,067 & 0 \\
\hline Rockets & 0 & 5,097 \\
\hline Turbojets & 49,609 & 0 \\
\hline Inlets & 13,264 & 0 \\
\hline Fuel Systems & 9,536 & 2,077 \\
\hline Fixed Equipment & 14,007 & 6,329 \\
\hline Empty Weight & 235,939 & 30,773 \\
\hline Useful/Consm. & 3,178 & 2,423 \\
\hline Propellant & 161,155 & 158,095 \\
\hline Payload & 200,700 & 8,000 \\
\hline Gross Weight & 602,388 & 199,301 \\
\hline
\end{tabular}

The experimental scramjet engine on the $\mathrm{P} / \mathrm{X}$ spaceplane would provide direct evidence in the Mach 6 to 10 range for developing prototype ram/scramjet propulsion system. Initial flight experiences with orbiter- $\mathrm{R}$ would lead to the development of lowmaintenance, 50-mission rocket engines.

Primarily, the integration of turbojet and ramjet engines, ramjet-scramjet transition, vehicle performance at low-hypersonic Mach numbers, stage separation, and the rocket propulsion system (with a 50mission operability at low maintenance) are the risk items. These are relatively minor risks compared to the technical risk of developing a commercially viable, SSTO-R vehicle for IOC in 2012.

Since the access to space study, ${ }^{8}$ hypersonic technologies have advanced and new hypersonic technologies have been developed. Today, all required technologies for developing the proposed TSTO spaceplane, that would stage the orbiter at Mach 6 with air-breathing propulsion on the launcher, are believed to be at technology readiness level ${ }^{8}$ (TRL) of at least 5 . All TRLs can be brought to level 6 within the next 3 years.

\section{Performance at Mach 10 Staging}

The flight trajectory of the spaceplane with a $25,000-\mathrm{lb}$ payload during ascent is a typical airplane/air-breathing type trajectory with an initial, low-speed acceleration at low flight-path angle (fig. 16). The transonic flight regime is flown at an approximate dynamic pressure of $1,250 \mathrm{lb} / \mathrm{ft}^{2}$ to reduce the induced aerodynamic drag at the transonic minimum acceleration or pinch point. The dynamic pressure is about $1,500 \mathrm{lb} / \mathrm{ft}^{2}$ from Mach 2 to 4 for supersonic climb. Subsequently, the dynamic pressure is gradually increased to approximately 2,100 $\mathrm{lb} / \mathrm{ft}^{2}$ during acceleration at hypersonic speeds.

A 2.0g pull-up maneuver is initiated at Mach 10 and at an altitude of $95,000 \mathrm{ft}$, to lower dynamic pressures and achieve the optimal launching flight path angle for the orbiter vehicle (fig. 17). The MECO is at Mach 10.4 and at an altitude of $106,000 \mathrm{ft}$. The orbiter is launched at an altitude of approximately 140,000 ft. and the dynamic pressure of $300 \mathrm{lb} / \mathrm{ft}^{2}$. After second-stage separation, the launcher continues its unpowered ascent and initiates a $66.4^{\circ}$ bank to begin the return-to-launchsite maneuver. Maximum attained altitude is approximately $200,000 \mathrm{ft}$. During entry, a turn to the cruise-back heading angle is completed and the launcher cruises at maximum specific-range Mach number (2.0), using the low-speed turbojets to return to its launch site. The orbiter rapidly climbs and accelerates to approximately Mach 27.5, when it reaches the MECO condition and then coasts to the desired orbit. Figure 17 also shows the orbiter entry 
flight. It uses low, initial-entry flight-path angle to ensure that heat loads are within the design margin.

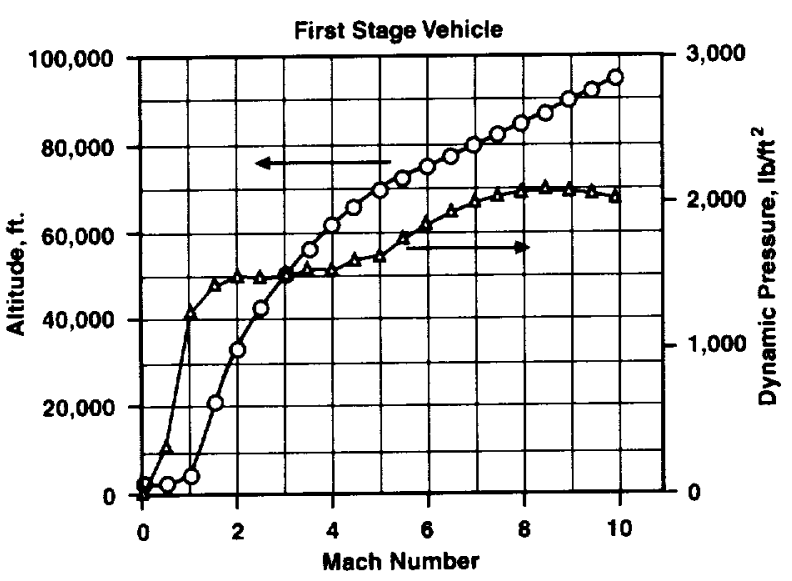

Figure 16. Trajectory and dynamic pressure experienced by the launcher.

A possible abort mission for the spaceplane consists of taking off, climbing, accelerating to the launch point, performing the pull-up maneuver, and then aborting the launch and returning to the takeoff point (fig. 18).

When a decision is made to abort after MECO, and just before reaching the launch point, the spaceplane begins a roll to 66.4 , reaches maximum altitude of $206,000 \mathrm{ft}$ at Mach 8.76, and then begins to descend. During atmospheric entry, the spaceplane experiences maximum dynamic pressure of $730 \mathrm{lb} / \mathrm{ft}^{2}$ at Mach 7.5 and at an altitude of $106,000 \mathrm{ft}$. It reaches the maximum down range at Mach 6.4 and an altitude of $111,000 \mathrm{ft}$. After completing the U-turn, at normal loads less than $2.5 \mathrm{~g}$, it is travelling at Mach 2 and is at an altitude of $75,000 \mathrm{ft}$. At this point, it begins turbojet power-on cruise back to the takeoff point at the best specific range Mach number. During the abort phase, the launcher continues to carry the orbiter at its full launch weight.

If a launcher engine shuts down at any point during the trajectory, the spaceplane can return safely to the airport of origin the same as an airplane would. The launch-abort mission impacts the sizing of the thermal protection system and fuel load on the launcher.

The bending moment distributions on the launcher are shown in figure 19 for power-on/tanks full, poweroff/tanks full (abort condition), power-on/tanks empty (MECO condition), and power-off/tanks empty (entry condition). For all loading conditions, the launcher is carrying the orbiter at its launch weight. Bending moments are distributed fairly symmetrically around the center of mass for all conditions.

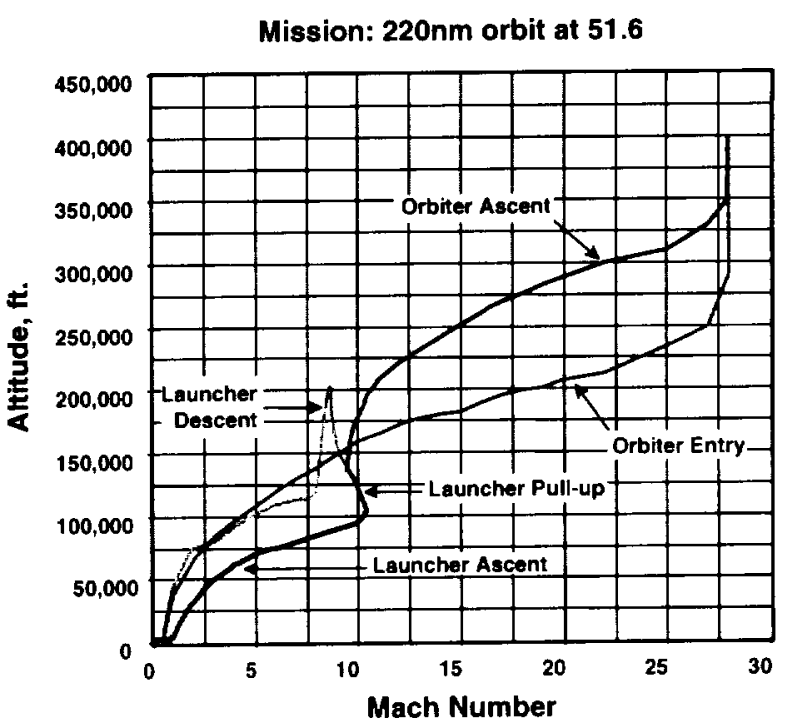

Figure 17. Launcher and orbiter trajectories.

Figures 20 and 21 show temperature time histories at specific, in-depth locations on the launcher and orbiter. Temperature histories at the surface, at the bond line between the external insulation and the internal cryogenic insulation, and at the interior surface of the internal cryogenic structures are plotted. The peaks in profiles for external surfaces are associated with peak heating environments encountered by these structures. The bond line temperature remains below $350 \mathrm{~F}$, a design constraint. The resulting internal temperatures on the launcher's cryo-structures are well below material allowable limits.

\section{Internal Rate of Return}

Table 4 compares a spaceplane designed to stage at Mach 5 with a 25,000-lb payload on the orbiter, with a spaceplane whose orbiter is launched either at Mach 5 or 10. The TOGW of the latter spaceplane (the commonality spaceplane) and the weight of its orbiter are the same, whether the payload weight is $8,000 \mathrm{lb}$ launched at Mach 5 or 41,000 lb launched at Mach 10. The launch cost per pound of payload, for launching a payload weighing $25,000 \mathrm{lb}$, with the commonality spaceplane is approximately 0.92 percent of that for the baseline spaceplane (table 4 ). 


\section{Mission: $220 \mathrm{~nm}$ at $51.6^{\circ}$}

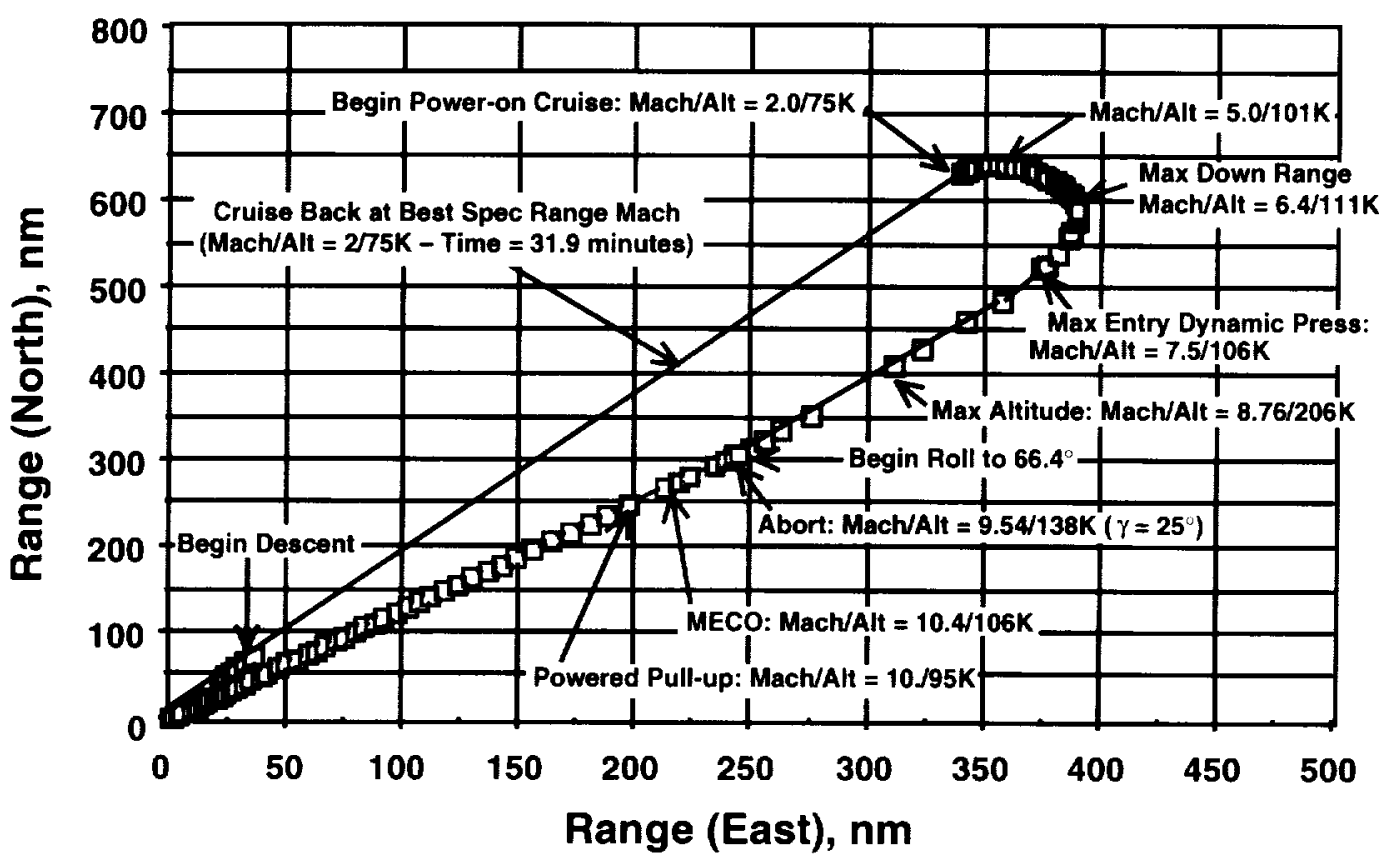

Figure 18. Spaceplane launch, abort, and recovery ground track.

First Stage Bending Moment vs. Body Station

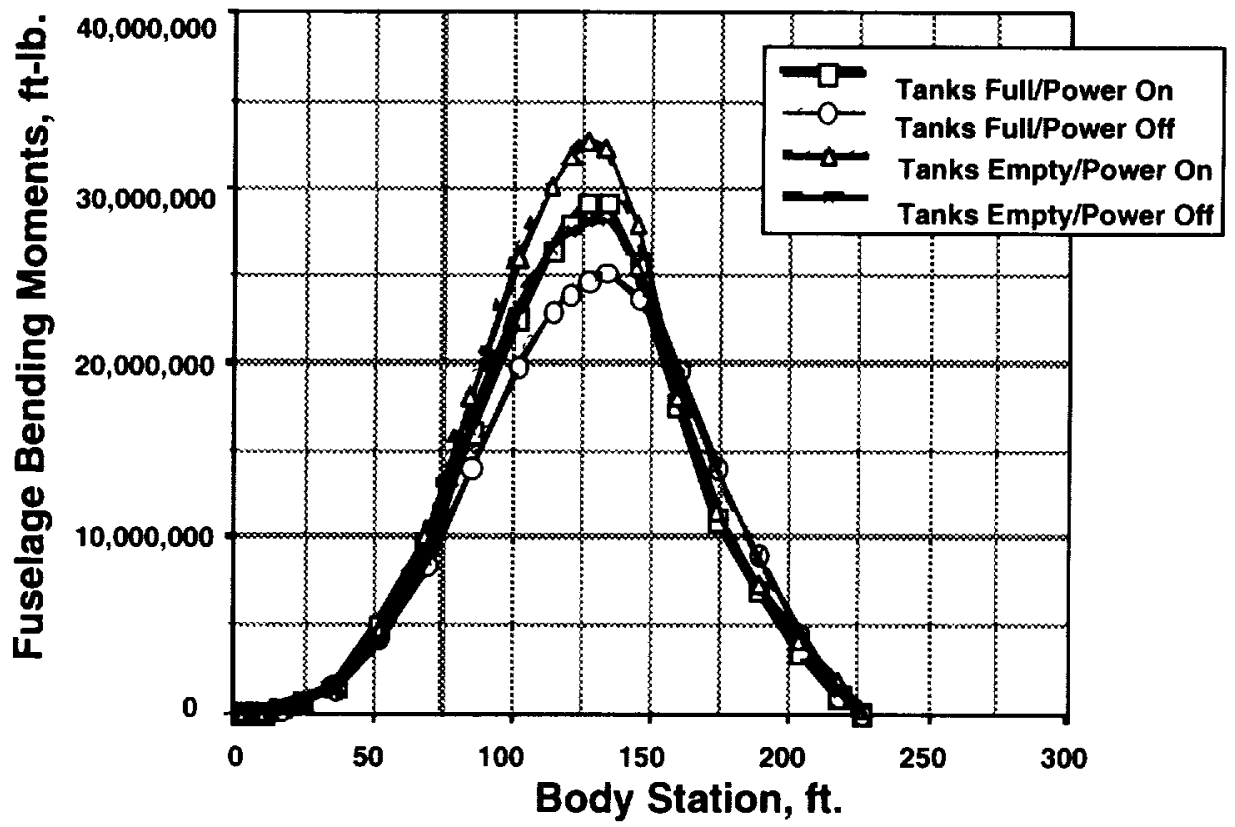

Figure 19. Launcher bending moments. 


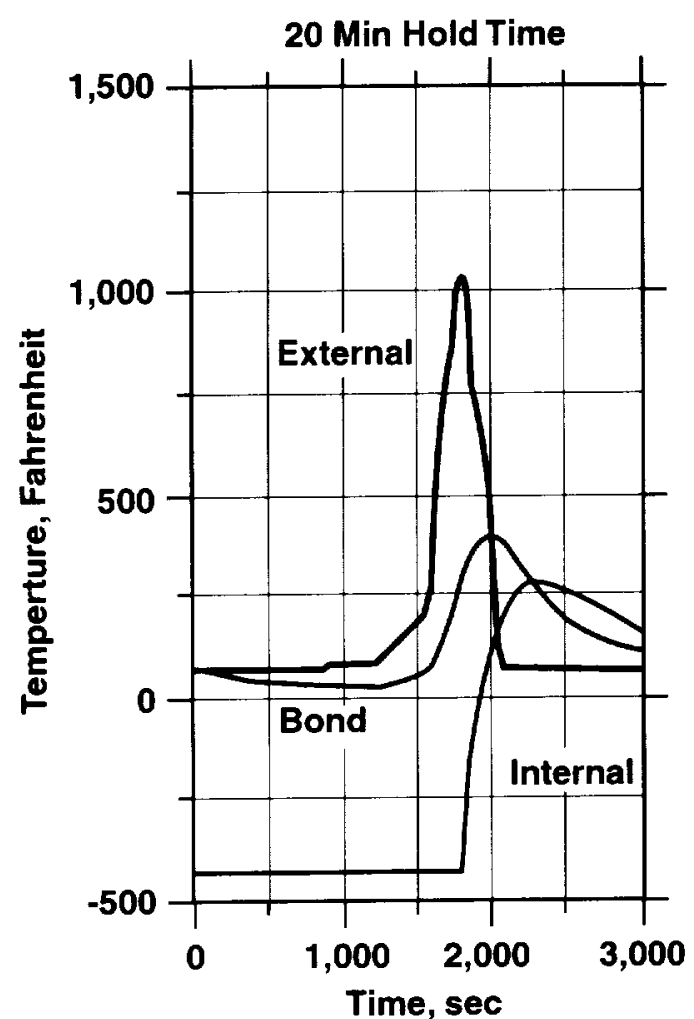

Figure 20. Launcher surface and bond-line temperature histories at $25 \mathrm{ft}$ from the nose on the bottom surface.

The acquisition cost is for a fleet of five operational launchers and seven operational orbiters plus two groundtest vehicles, one for the launcher and one for the orbiter. Thirty-nine flights per year are operated for 22 years. Cost estimates are in 1992 U.S. dollars.

The LCC for each of the three systems (all-rocket SSTO, air-breathing/rocket SSTO, and air-breathing plus allrocket TSTO) considered under option 3 of the NASA access-to-space study ${ }^{8}$ are almost the same as those for the other two systems (fig. 22).

The TSTO spaceplane is a low-risk concept, requiring low-risk technology, compared to the SSTO rocket vehicle or the SSTO air-breathing/rocket vehicle. The sensitivity of the SSTO rocket vehicle to small changes in dry weight and in specific impulse is significantly larger than that of the TSTO spaceplane (fig. 23), because the SSTO rocket has a very high fuel fraction requirement, approximately 90 percent.

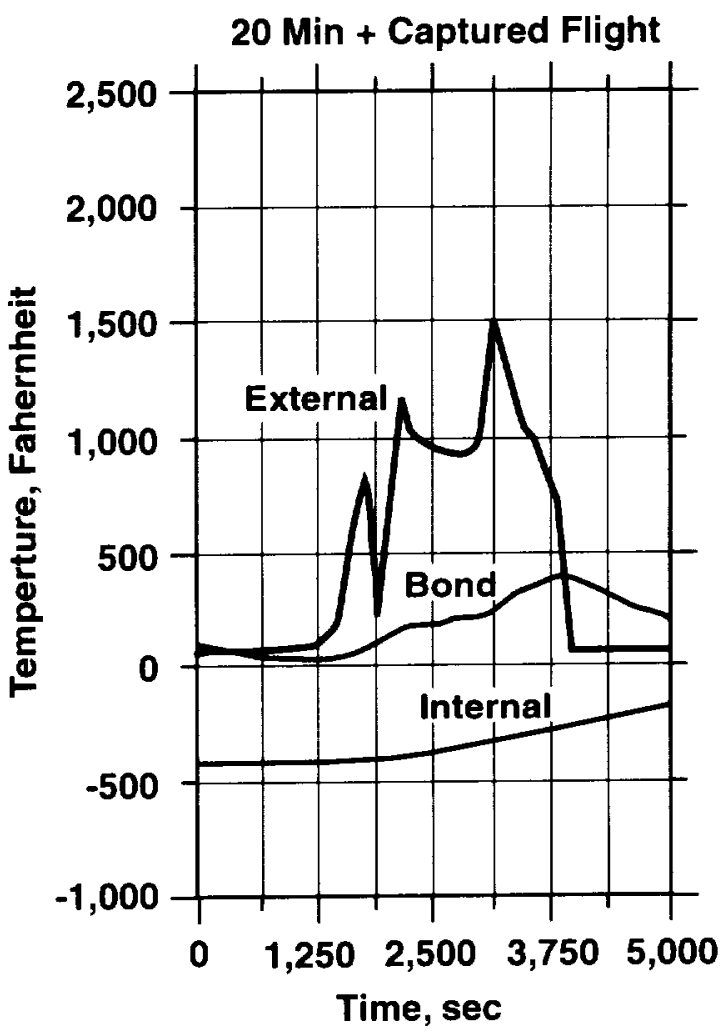

Figure 21. Orbiter surface and bond-line temperature histories at $25 \mathrm{ft}$ from the nose on the bottom surface.

Table 4. Weight and LCC comparisons of TSTO spaceplanes.

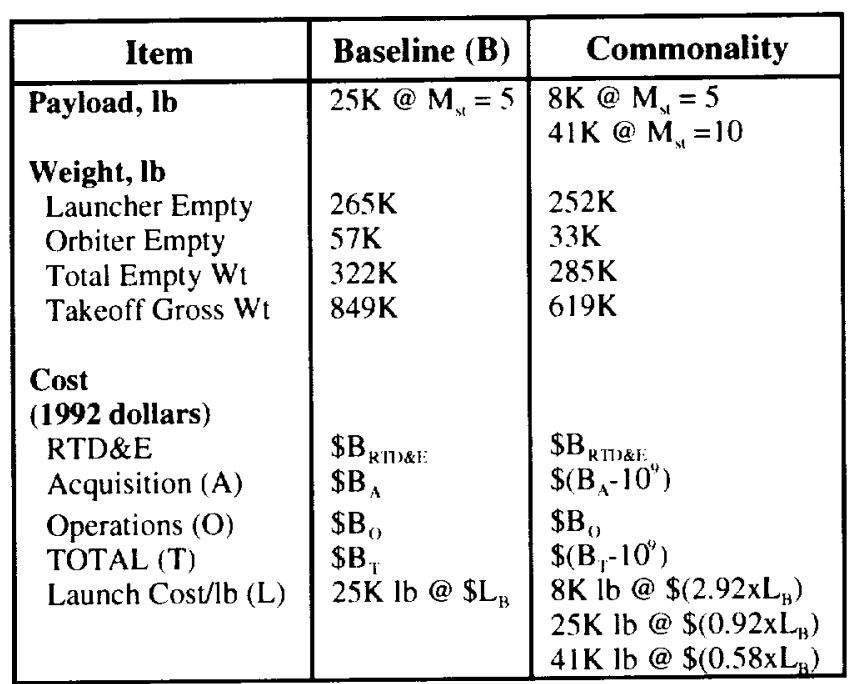


MTose

Aequisition

Dprations

Total Life-Cycle Costs

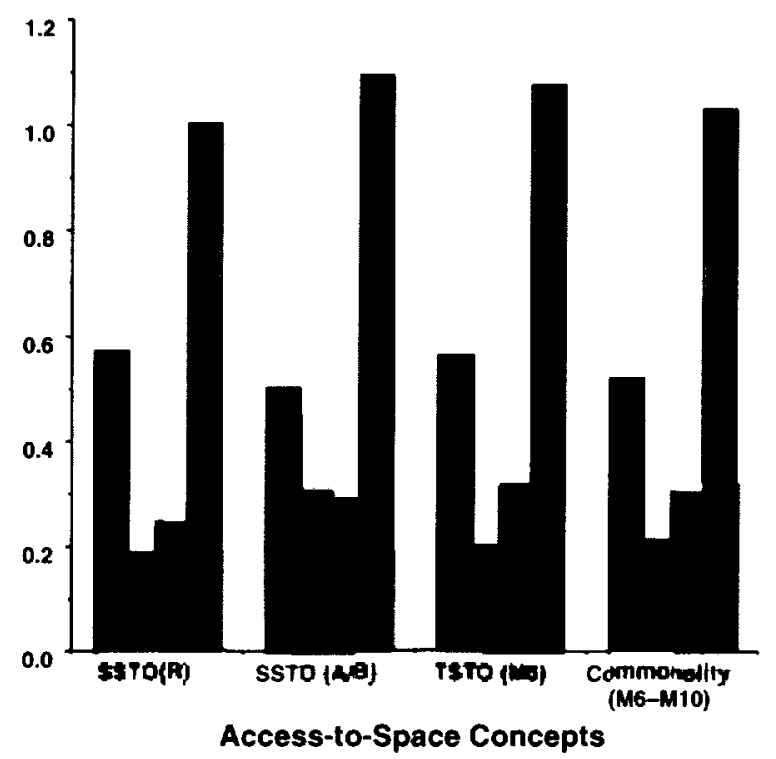

Figure 22. LCC for the access-to-space study vehicles.

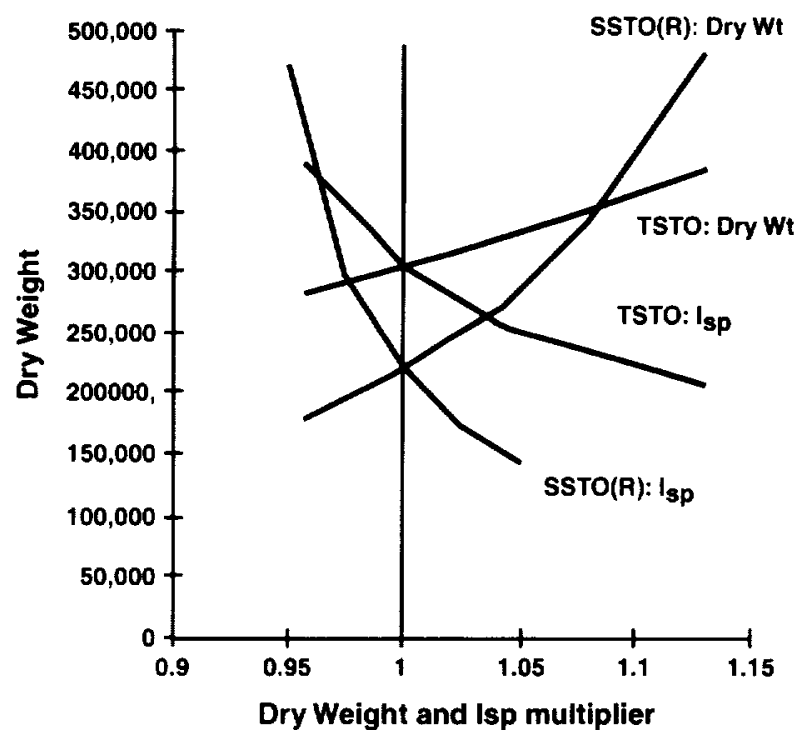

Figure 23. Sensitivities of SSTO rocket-powered vehicle and TSTO spaceplane. ${ }^{9}$

A new launch vehicle meeting commercial requirements and interests must create profit to be a commercial success; that is, it should be economically viable. The RTD\&E and acquisition costs of the new system, added to the overall costs of continued operation of the space shuttle and the existing fleet of expendable launch vehicles, leads to the increase in the launch vehicle total cost (fig. 24). When a new fleet of reusable vehicles replaces a present fleet, the new flect would greatly reduce operating costs.

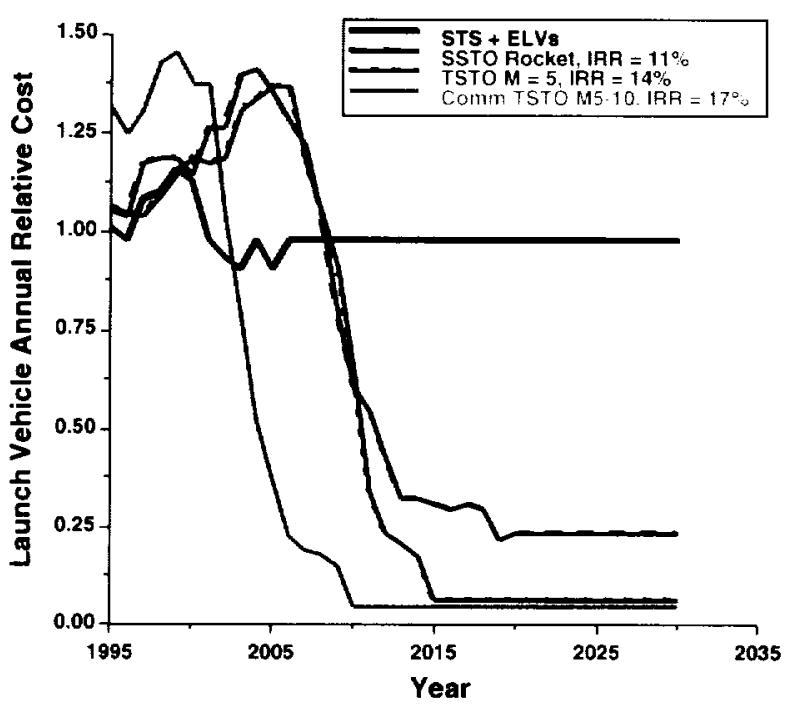

Figure 24. Funding streams over time, with internal rate of return (adapted from reference 9 ).

The Mach 5 to 10 commonality TSTO spaceplane substantially reduces the need for experimental vehicles. Additionally, the commonality spaceplane, with early operations at $\mathbf{M}_{\mathrm{st}}=5$, and with subsequent operations at $\mathrm{M}_{\mathrm{sL}}=10$ 1-year later, saves 10s of billions of dollars over a 5-year period. ${ }^{9}$ The TSTO commonality spaceplane achieves operational status much earlier than the SSTO rocket vehicle and the TSTO Mach 5 staging spaceplane, because the latter vehicles are required to have a 5 -year technology program to reduce risk with flight demonstrations. In the case of the commonality spaceplane, technology development and risk reduction are carried out in flight, while light-weight payloads are launched to reduce total launch costs.

The SSTO rocket system was estimated to provide 11 -percent internal rate of return (IRR). The commonality spaceplane offers a 17-percent IRR. This rate is more than that provided by the SSTO rocket and the TSTO vehicle with Mach 5 staging. However, 17-percent IRR is not high enough for an economically viable launch system. 
To dramatically increase the safety and reliability, drastically lower the LCC of access to space, and to converge noncommercial/commercial requirements and interests for space launch may be difficult. As observed in reference 9, a 22-percent return on investment may be feasible, if the Government funds the first 2 years of the development program.

\section{Further Growth Potentials ${ }^{10}$}

The reusable and operationally flexible launcher provides vital access-to-space launch and hypersonic flight test services capability. However, the orbiter- $\mathrm{R}$ provides short-term economical benefits by achieving orbit for space missions, while orbiter-E (table 2) is used for further scramjet development. This orbiter serves as a testbed for conducting experiments and developments at high dynamic and heating loads, such as those related to full-scale structural panels and components, including scramjet engines. Orbiter-E is utilized as the $X-7$ and $X$ 15 planes were.

The Mach 5 to 24 range is divided into three ranges, low(Mach 5+ to 10), moderate- (Mach 10+ to 18), and highMach number (Mach $18+$ to 24 ) ranges. This division facilitates testing of the scramjet operation over the lowhypersonic Mach range, with the launcher and the incremental development of air-breathing propulsion with orbiter-E at moderate- and high-hypersonic Mach numbers. This divide-and-conquer philosophy significantly reduces development and flight-test risks.

Orbiter-E is designed to go from Mach 9+ to 24, and is primarily a rocket-powered vehicle with only one replaceable air-breathing engine. The orbiter is designed to fly, when required, selected parts of orbiter-A's airbreathing trajectory. The configurations of orbiter- $E$ and orbiter-A may be different from that for orbiter-R.

The development of the propulsion system with orbiter-E is accomplished in three steps of increasing technological challenges: from Mach 9 to 12 , Mach $12+$ to 18 , and Mach $18+$ to 24 . Once this system is developed in the Mach 9 to 12 range, the prototype orbiter- $A$ is built. When the scramjet is developed in the Mach $12+$ to 18 range, the air-breathing range of orbiter-A can be extended, or the development of a prototype SSTO spaceplane with air-breathing/rocket propulsion can be undertaken.

Orbiter-E is not built until the hypersonic propulsion system performs satisfactorily in the launcher, up to Mach 10 , and is well understood. While the launcher and orbiter- $\mathrm{R}$ are designed, built, tested, evaluated, and made operational, a program is carried out for advancing the hypersonic facility capability and for improving appropriate, nonintrusive, flow-diagnostic technology applicable to the hypersonic environment. Flight-test data from flights of the launcher in the low-hypersonic Mach number range would improve computational-design technology and calibrate ground-test data. These advances and enhancements would help in the design of an experimental air-breathing propulsion flow path for orbiter-E, with a high level of confidence in its design. Flight tests of this truly experimental vehicle in the moderate- and high-Mach-number ranges and the advances in hypersonic facilities would result in a high level of confidence in the design of orbiter-A.

Rocket and air-breathing propulsion options are pursued. These propulsion systems and the proposed vehicles open up, for example, the following further growth potentials and multiple avenues, any one of which may be pursued with a high level of confidence: (1) replacement of orbiter-R with orbiter-A, (2) development of an airbreathing/rocket SSTO vehicle, (3) development of an allrocket SSTO vehicle , (4) development of a hypersonic cruiser, (5) development of an unpiloted orbiter, (6) development of an expendable, unpiloted orbiter for highenergy orbits, and ( 7 ) development of reusable orbiters for specific payloads.

\section{Concluding Remarks}

The foremost objective is to greatly reduce cost and substantially improve safety and reliability for access to space. In the near term, this objective can be best met using a TSTO concept with a hypersonic air-breathing propulsion system on the first stage.

Spaceplanes with low-risk technologies and built-in growth potential and aircraft-like operations provide the most return on investment. The conceptual TSTO P/Xspaceplane is closest to meeting economic requirements-a 20-percent rate of return on investment. This spaceplane significantly reduces risk, increases margin, and maintains the SSTO option.

The P/X-spaceplane launcher assists the development of hypersonic air-breathing propulsion and meets the desired access-to-space requirements near-term. The orbiter assists in the development of long-life, low-maintenance rocket engines. This strategy offers a number of advantages; is technology-driven, opens up multiple future avenues, provides short-term benefits, has built-in growth potential, and is achievable. 
The TSTO spaceplane, with air-breathing propulsion on the first stage, appears to be the correct choice for the development of the next-generation, reusable launch vehicles. This concept could be a serious candidate for IOC in circa 2012, with Mach 6 staging. The TRLs are believed to be at or above level 5 for this spaceplane. The prototype spaceplane with Mach 10 staging could be operational in circa 2014.

\section{References}

1. Augenstein, B. W., Harris, E. D., with Aroesty, J., et al., "The National Aerospace Plane (NASP): Development Issues for the Follow-on Vehicle," Executive Summary, RAND, R3878/1-AF, 1993.

2. Hallion, R. P. and Young, J. O., "Space Shuttle: Fulfillment of a Dream," The Hypersonic Revolution, Vol. II, edited by R. P. Hallion, Special Staff Office, Aeronautical Systems Division, Wright-Patterson Air Force Base, Ohio, 1987.

3. "National Aero-Space Plane, Restructuring Future Research and Development Efforts," GAO, NSIAD-93-71, U.S. Government Accounting Office, 1993.

4. Rich, B. R. and Janos, L., Skunk Works: A Personal Memoir of My Years at Lockheed, Little Brown \& Co., Boston, MA, 1994.

5. Dornheim, M. A., "Engineers Anticipated X-33 Tank Failure," Aviation Week and Space Technology, 15 November 1999.

6. "Final Report of the X-33 Liquid Hydrogen Tank Test Investigation Team," NASA George C. Marshall Space Flight Center, May 2000.

7. Bekey, I, "Forget About Shuttle Upgrades, Go With RLVs," Aviation Week \& Space Technology, 24 April 2000 .

8. "Access to Space, Advanced Technology Team Final Report," Vol. 1, Executive Summary, National Aeronautics and Space Administration, July 1993.

9. Gregory, T., Bowles, J., and Ardema, M., "TwoStage-To-Orbit Air-breathing and Rocket System for Low Risk, Affordable Access to Space," SAE 1994 Transactions, Journal of Aerospace, Section 1, Vol. 103, 1995, pp. 189-201; also SAE Paper 94-1168, April 1994.
10. Mehta, U. B., "Strategy for Developing AirBreathing Aerospace Plane," Journal of Aircraft, Vol. 33, No. 2, March-April 1996. Errata in Vol. 33, No. 4, July-August 1996, p. 840. (This paper is an updated and shortened version of "AirBreathing Aerospace Plane Development Essential: Hypersonic Propulsion Flight Tests (Invited)," Proceedings of the 2nd European Symposium on Aerothermodynamics for Space Vehicles, ESTEC, Noordwijk, The Netherlands, November 21-23, 1994, ESA SP-367, February 1995.)

11. Morris, R. E. and William, N. B., "A Study of Advanced Air-breathing Launch Vehicles With Cruise Capability," Vols. I-VI, NASA CR 73194-73199, 1968.

12. Novichov, N., "At Hypersonic Speeds," FASTCID(RS)T-0972-92, Foreign Aerospace Science and Technology Center, WPAFB, Ohio, Translated from Ekho Planety, Vol. 42, No. 237, 17-23 October 1992.

13 . Faye, J. A. and Riddell, F. R., "Theory of Stagnation Point Heat Transfer in Dissociated Air," Journal of Aerospace Sciences, Vol. 25, No. 121, 1958, pp. 54-67.

14. Lee, L., "Laminar Heat Transfer Over Blunt Nosed Bodies at Hypersonic Flight Speeds," Jet Propulsion, Vol. 26, No. 4, April 1956.

15. Windhorst, R., Ardema, M., and Bowles, J., "Minimum Heating Entry Trajectories for Reusable Launch Vehicles," Journal of Spacecraft and Rockets, Vol. 35, No. 5, September-October, 1998, pp. 672-682.

16. "Hypersonic Research Facilities (HyFAC) Study," Vol. V, Limited Rights Data, NASA CR 114330 , 1970.

17. Private Communication, Integrated System Analysis Team (ISAT), NASA Langley Research Center, 2000. 
Public reporting burden for this collection of information is estimated to average 1 hour per response, including the time for reviewing instructions, searching existing data sources gathering and maintaining the data needed, and completing and reviewing the collection of information. Send comments regarding this burden estimate or any other aspect of this collection of information, including suggestions for reducing this burden, to Washington Headquarters Senvices, Directorate for intormation Operations and Reports, 1215 Jefferson Davis Highway, Suite 1204, Arlington, VA 22202-4302, and to the Ottice of Management and Budget, Paperwork Reduction Project (0704-0188), Washington, DC 20503.

\begin{tabular}{|l|c|c|}
\hline 1. AGENCY USE ONLY (Leave blank) & $\begin{array}{c}\text { 2. REPORT DATE } \\
\text { February } 2001\end{array}$ & $\begin{array}{c}\text { 3. REPORT TYPE AND DATES COVERED } \\
\text { Technical Memorandum }\end{array}$ \\
\hline
\end{tabular}

4. TITLE AND SUBTITLE

A Two-Stage-to-Orbit Spaceplane Concept with Growth Potential

6. AUTHOR(S)

Unmeel B. Mehta and Jeffrey V. Bowles

Ames Research Center

Moffett Field, CA 94035-1000

9. SPONSORING/MONITORING AGENCY NAME(S) AND ADDRESS(ES)

National Aeronautics and Space Administration

Washington, DC 20546-0001

\section{FUNDING NUMBERS}

\section{3-74}

8. PERFORMING ORGANIZATION REPORT NUMBER

A-00V0029

10. SPONSORING/MONITORING AGENCY REPORT NUMBER

NASA/TM-2001-209620

This paper is presented as AIAA Paper 2001-1795 at the AIAANNAS-NASDA-ISAS 10th International Space Planes and Hypersonic Systems and Technologies Conference, 24-27 April 2001, Kyoto, Japan. Point of Contact: Unmeel B. Mehta, Ames Research Center, MS 229-3, Moffett Field, CA 94035-1000 (650) 604-6744

128. DISTRIBUTION/AVAILABILITY STATEMENT

12b. DISTRIBUTION CODE

Unclassified - Unlimited

Subject Category 16 Distribution: Standard

Availability: NASA CASI (301) 621-0390

13. ABSTRACT (Maximum 200 words)

A two-stage-to-orbit (TSTO) spaceplane concept developed in 1993 is revisited, and new information is provided to assist in the development of the next-generation space transportation vehicles. The design philosophy, TSTO spaceplane concept, and the design method are briefly described. A trade study between cold and hot structures leads to the choice of cold structures with external thermal protection systems. The optimal Mach number for staging the second stage of the TSTO spaceplane (with air-breathing propulsion on the first stage) is 10, based on life-cycle cost analysis. The performance and specification of a prototype/ experimental (P/X) TSTO spaceplane with a turbo/ram/scramjet propulsion system and built-in growth potential are presented and discussed. The internal rate of return on investment is the highest for the proposed TSTO spaceplane, vis-à-vis a single-stage-to-orbit (SSTO) rocket vehicle and a TSTO spaceplane without built-in growth. Additional growth potentials for the proposed spaceplane are suggested. This spaceplane can substantially decrease access-to-space cost and risk, and increase safety and reliability in the near term. It can be a serious candidate for the next-generation space transportation system.

14. SUBJECT TERMS

Access to Space, Space Transportation, Spaceplane, Single-Stage-to-Orbit, Two-Stage-to-Orbit, Air-breathing Propulsion

15. NUMBER OF PAGES

17. SECUAITY CLASSIFICATION OF REPORT

Unclassified

8. SECURITY CLASSIFICATION OF THIS PAGE

Unclassified

19.

SECURITY CLASSIFICATION OF ABSTRACT 


$-=$ 